\title{
ESTILO Y TIEMPO. UN ESTUDIO SOBRE LA CRONOLOGÍA DEL ESTILO CERÁMICO FAMABALASTO Negro GrabAdo Del Noroeste ARgENTINO MEDIANTE DATACIONES RADIOCARBÓNICAS
}

\author{
Valeria Palamarczuk ${ }^{1}$ y Catriel Greco ${ }^{2}$
}

\section{* Introducción}

Resumen

Considerando como punto de partida las diferentes hipótesis referidas a la temporalidad de la alfarería estilo Famabalasto Negro Grabado del Noroeste Argentino, se evalúan un total de 47 fechados radiocarbónicos en sitios de los valles Calchaquí, Hualfín, Andalgalá y - principalmenteYocavil, con el propósito de ajustar la cronología de este particular estilo alfarero. El análisis contextual crítico propuesto considera los niveles de asociación entre la muestra orgánica fechada y el evento a datar y también los niveles de asociación entre el evento datado y el conjunto cerámico espacialmente vinculado, a la luz de la información disponible.

Tomando en cuenta solamente los datos radiocarbónicos con buen nivel de asociación a cerámicas de estilo Famabalasto Negro Grabado, se propone ubicar el lapso de su producción a nivel regional hacia los inicios del siglo XIV y mediados del siglo XVI.

Palabras claves: fechados radiocarbónicos - valle de Yocavil Noroeste Argentino.

\begin{abstract}
Considering as a starting point the different hypothesis referred to the temporality of the Famabalasto Negro Grabado pottery from the Argentinean Northwest, a total of 47 radiocarbon dates from the Calchaquí, Hualfín, Andalgalá and - principally- Yocavil valleys are evaluated with the goal of adjusting the chronology of this particular pottery style. The critical contextual analysis proposed considers the association levels between the dated organic sample and the event to be dated, and also the levels of association between the dated event and the pottery associated to it. Taking into account only the radiocarbon data with good levels of association to the Famabalasto Negro Grabado pottery style, we propose to locate the period of its production to a regional level between the beginnings of the 14th century to the mid of the 16th century.
\end{abstract}

Key words: Radiocarbon dates - Yocavil Valley - Argentinean Northwest.
En tanto producciones artísticas conforme modelos o patrones estéticos, efectuadas por personas, grupos o sociedades que están histórica y espacialmente situados, los estilos alfareros arqueológicos se reconocen $-y$ luego se definen en sus múltiples características- en base a regularidades en las formas, los materiales, las técnicas y los diseños (Alcina Franch 1982). Esta identificación a partir de regularidades, que está en la base de la definición de estilo, no excluye el carácter inconstante, móvil y dinámico de los mismos, en cuyas entidades y transformaciones buscamos e indagamos aquellos elementos que nos permitan acercarnos al conocimiento de distintos aspectos de la organización social, la economía, la política y las ideologías que caracterizaron a las antiguas formaciones sociales que los produjeron.

La definición de estilos cerámicos y su ubicación en el espacio y el tiempo, elementos necesarios para la elaboración de secuencias arqueológicas regionales, es un tema en el que se ha avanzado de modo progresivo, aunque con interrupciones que llegaron a durar décadas, desde los inicios de la práctica arqueológica en el Noroeste Argentino. A partir de la década del 50 y hasta mediados del 70 , el tema fue central para la arqueología de la región, en especial para el área valliserrana (González 1950-55; Cigliano 1956-57, 1958; Perrotta y Podestá 1974 Ms, 1975; Weber 1978, entre otros).

Recibido: septiembre 2009. Aceptado: diciembre 2011.

\footnotetext{
${ }^{1}$ CONICET, Museo Etnográfico J. B. Ambrosetti, Moreno 350 (1091), Ciudad Autónoma de Buenos Aires, ARGENTINA. Email: valepala@ yahoo.com.ar

2 CONICET, Museo Etnográfico J. B. Ambrosetti, Moreno 350 (1091), Ciudad Autónoma de Buenos Aires, ARGENTINA. Email: catrielgreco@ gmail.com
} 
A su vez la distribución de los estilos cerámicos mayoritarios en el espacio regional fue un elemento muy importante, si bien no el único, para la identificación de amplios territorios o áreas de influencia de sociedades. Así, para el período Tardío, ${ }^{3}$ se delimitaron grandes ámbitos como Belén, Santa María, Sanagasta, Averías, Humahuaca, etc. (González 1977), por lo general nombrados del mismo modo que algún sector (valle, localidad) especialmente representativo y en lo cual se encuentra el estilo cerámico decorado más abundante en cada ámbito. Sin embargo, es bien sabido que estas sociedades, a lo largo de los varios siglos durante los cuales perduraron como sistemas integrados, elaboraron una multiplicidad de alfarerías en las que se pueden identificar variaciones estilísticas, tanto regionales como temporales. Algunos estilos cerámicos se produjeron a lo largo de todo el período Tardío, continuando su uso en el Incaico e Hispano-Indígena, mientras que otros tuvieron una temporalidad más breve.

La cerámica que hoy reconocemos como Famabalasto Negro Grabado (en adelante FNG) fue uno de los variados estilos minoritarios, ${ }^{4}$ producidos a lo largo de la "época tardía" (designación amplia que engloba al Tardío, los momentos de expansión incaica y los primeros momentos de la presencia española) por las sociedades del área valliserrana, cuyos territorios incluyeron algunos de los espacios comprendidos por los desarrollos regionales Santa María y Belén (Figura 1). En especial, fue producida y circuló con mayor intensidad en el valle de Yocavil y áreas colindantes en las que existían poblados o instalaciones santamarianas como el sur del valle del Cajón, Tafí y el piedemonte oriental de Tucumán. También, aunque son menos abundantes, se hallan manifestaciones del estilo en las zonas de Hualfín, Andalgalá y el valle Calchaquí.

3 De acuerdo con los esquemas de periodificación corrientes para el Noroeste Argentino, el período Tardío o de los Desarrollos Regionales se extiende entre los siglos X y XV y es equivalente al Intermedio Tardío tal como se lo entiende en la arqueología de Perú, Chile y Bolivia.

4 A partir de una búsqueda exhaustiva de piezas Famabalasto Negro Grabado en la bibliografía y en veinte museos, se logró reunir una muestra de solo 209 vasijas. Los análisis cuantitativos de conjuntos fragmentarios en algunos poblados tardíos de Yocavil indican que es un estilo minoritario, sin embargo en muchos contextos es el tercero en orden de abundancia, luego de las Ordinarias peinadas y las variantes Santa María. Se destaca que en general aparece en cantidades notablemente más elevadas que otros estilos minoritarios que se encuentran en los sitios (Palamarczuk 2011).
Se trata de una alfarería de paredes finas, coloración oscura heterogénea, superficies pulidas y con diseños incisos formando guardas en la mayoría de las piezas, diseños que eran rellenados con pigmentos minerales blancos que le conferían un realce singular. Su estética presenta singulares paralelismos con la metalurgia tardía del bronce con diseños en relieve: discos, campanas ovales o tan tanes y hachas elaboradas. Dentro de las variadas morfologías que se han identificado, predominan ampliamente los cuencos o pucos, de formas y dimensiones adecuadas para el servicio de alimentos y bebidas (Palamarczuk 2011) (Figura 2).

Pero más allá de su reconocimiento como una manifestación artística de las sociedades de la época tardía en esos ámbitos, ¿qué es lo que sabemos acerca de la vigencia temporal de este estilo en particular? Repasando en la bibliografía los antecedentes de investigación, podemos reconocer cuatro planteos (Figura 3) con diferentes niveles de consenso en la comunidad arqueológica:

a. La cerámica FNG pertenece a momentos que incluyen los finales del período Tardío y la época de expansión incaica en el NOA (Cigliano 1956-57; 1958; A. R. González 1992).

b. La cerámica FNG forma parte del patrimonio de las sociedades santamarianas y evidencia la persistencia de un tipo cerámico anterior a la organización de las mismas. Se trata de formas tardías - que comenzarían a elaborarse hacia el siglo noveno- de un horizonte de cerámicas grises y negras que se había extendido previamente por el noroeste hacia el siglo quinto o sexto DC (Serrano 1967; Ibarra Grasso 1967).

c. El estilo FNG comienza a elaborarse en el NOA a partir de la llegada de los incas y se incluye en el conjunto de estilos alfareros denominados "Inca Provincial" (Calderari y Williams 1991).

d.El estilo FNG es una producción propia del Tardío en Yocavil que continúa produciéndose y circulando durante el período Inca e inclusive el de contacto Hispano-Indígena (Tarragó 1995; Palamarczuk y Manasiewicz 2009 [2001]).

Las nociones en torno a la cronología pueden entonces agruparse en dos posturas básicas. Por un lado está 


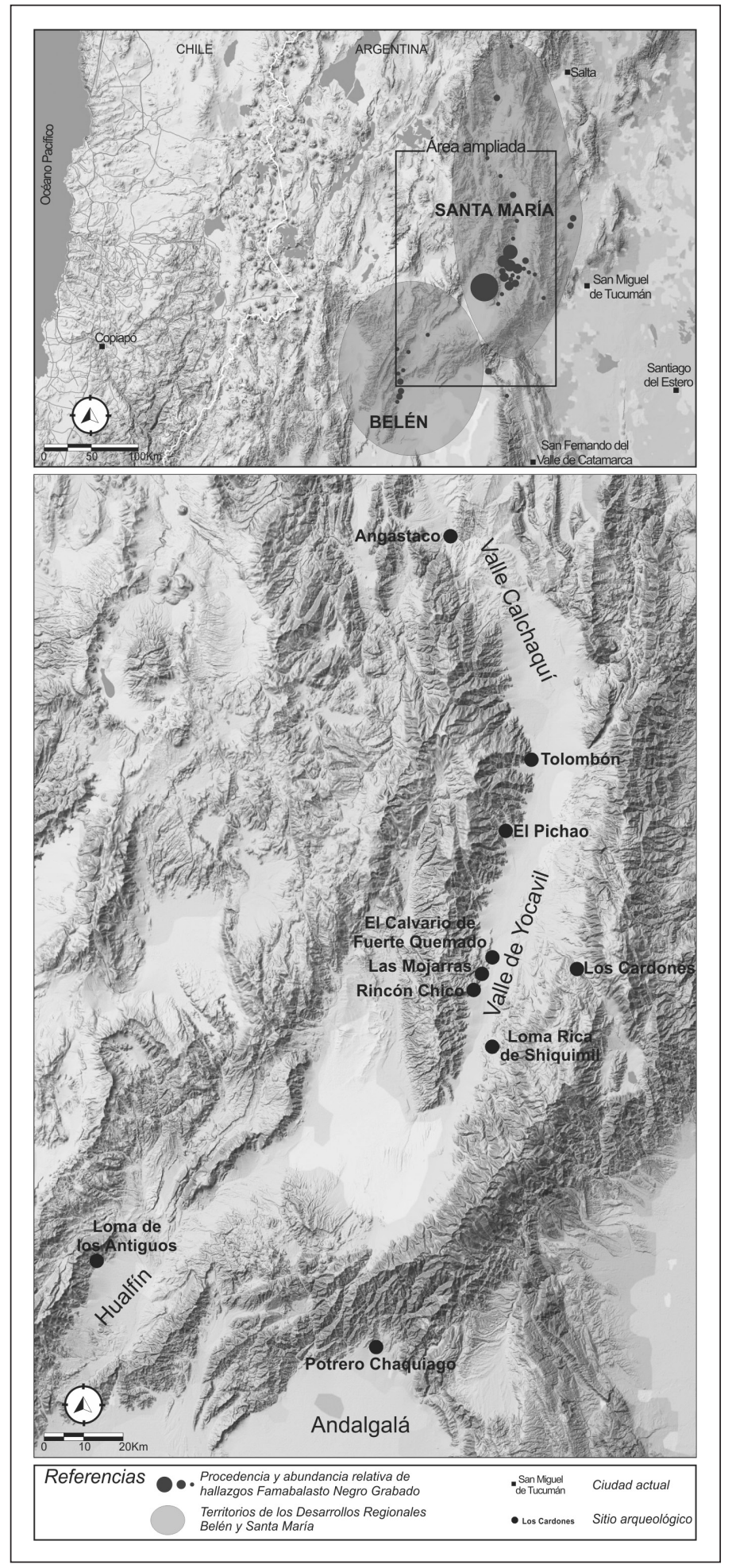

Figura 1. Mapa superior: distribución geográfica de hallazgos de alfarería Famabalasto Negro Grabado sobre una muestra de 209 ejemplares de museos y menciones bibliográficas. Las áreas marcadas con óvalos muestran los territorios de los Desarrollos Regionales Belén y Santa María, de acuerdo con González (1977). Mapa inferior: sitios mencionados en el texto. 


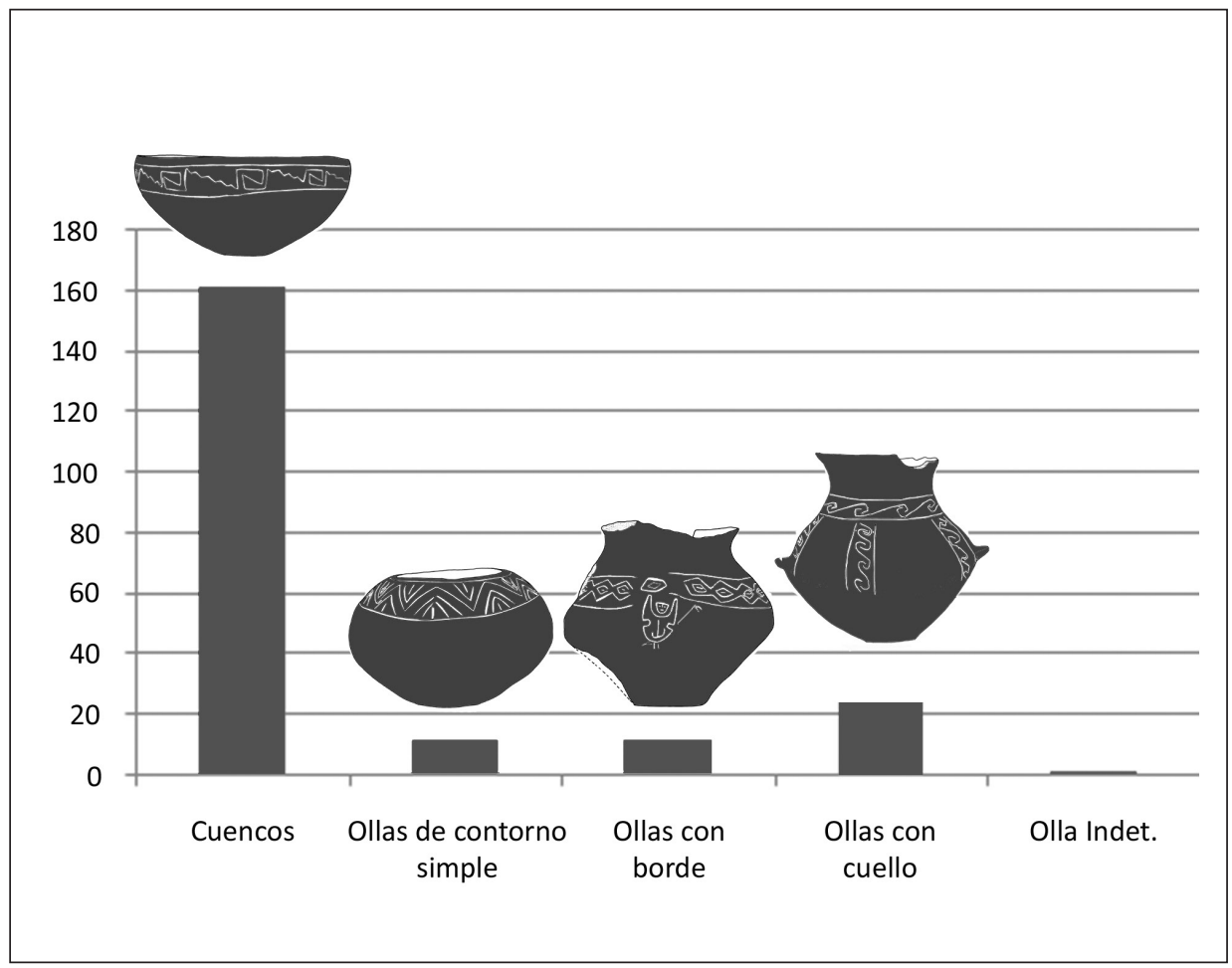

Figura 2. Ejemplos de vasijas estilo Famabalasto Negro Grabado y frecuencias de cada grupo morfológico en una muestra de 209 vasijas. Nótese el gran predominio de los cuencos con relación a los restantes grupos morfológicos.

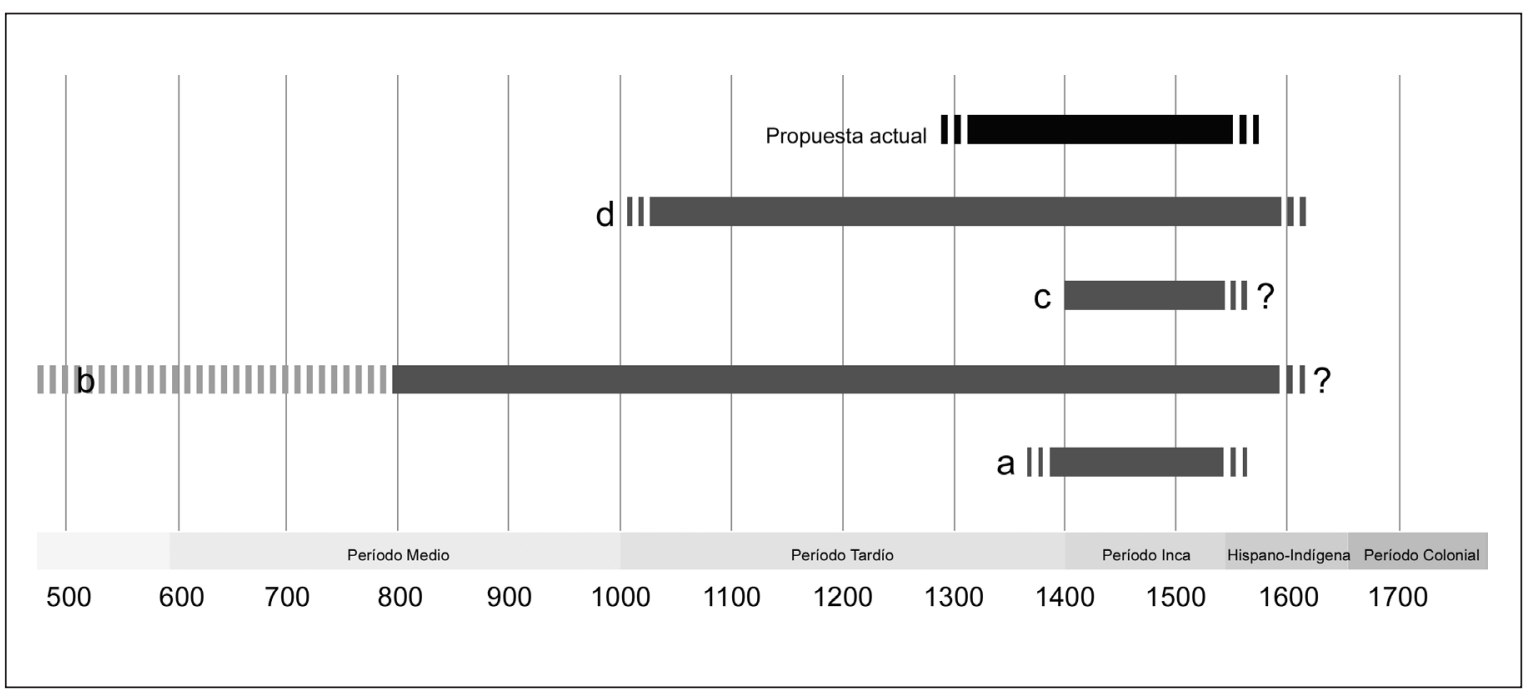

Figura 3. Representación idealizada de las diferentes propuestas de ubicación cronológica del estilo Famabalasto Negro Grabado, a: Cigliano 1956-57, 1958; González 1992; b: Serrano 1967; Ibarra Grasso 1967; c: Calderari y Williams 1991; d: Tarragó 1995; Palamarczuk y Manasiewicz 2001. 
la visión que ubica los inicios del estilo en la época de la expansión incaica en el NOA, por el otro, la idea según la cual éste se origina con anterioridad a dicho fenómeno expansivo, durante el período Tardío local. ${ }^{5}$ Ambas nociones encierran, además de un diferente contenido cronológico, una concepción profundamente dispar respecto del carácter de la estética que define al estilo, sea ésta autóctona - de raigambre local e inclusive ancestral presantamariana sensu Scattolin (200o) - o foránea - de raigambre extra local e introducida en la zona por los incas.

Habiendo ideas dispares, la cronología del estilo se presenta como un problema cuya definición es indispensable si queremos ubicar históricamente su producción. Desde un punto de vista práctico, esta ambigüedad reduce también la utilidad de los hallazgos FNG como elementos útiles para la inferencia de la antigüedad de los contextos arqueológicos en los que se encuentra.

Ante este estado de la cuestión, el propósito de nuestro trabajo fue lograr un ajuste cronológico de esta particular producción alfarera, empleando la información radiocarbónica actualmente disponible. ${ }^{6}$ Para ello se recurrió a la bibliografía publicada e inédita y también se proyectaron trabajos de campo orientados hacia la obtención de información relevante para este problema.

\section{* Metodología}

El análisis que desarrollamos es una parte dentro de un diseño metodológico holístico para el estudio de un estilo alfarero, que implica la consideración de la totalidad de datos disponibles sobre aquel en publicaciones, colec-

5 Durante la segunda mitad del siglo XX, diferentes investigaciones arqueológicas e históricas se han basado en una cronología fundada en datos históricos para la expansión inca en el Collasuyu que ubicaba hacia 1470, durante el reinado de Topa Inca, el avance imperial hacia el sur. Sin embargo, la temporalidad del proceso está siendo revisada, tomando en cuenta información arqueológica, favoreciendo la propuesta de los inicios del siglo XV para los comienzos de dicha expansión en el NOA. Esta versión es la que empleamos para elaborar la Figura 3.

6 Otra parte importante del análisis para la definición cronológica del Famabalasto Negro Grabado, que complementa el presente aporte, se basó en el estudio de asociaciones en un total de 37 contextos funerarios (Palamarczuk 2011). Los puntos más salientes de este análisis se tomarán en cuenta en las conclusiones. ciones de museos y los recuperados por el propio equipo de investigación. El enfoque se sustenta en la descripción profunda de aspectos tecnológicos, morfológicos e iconográficos, en la contextualización temporal y espacial de acuerdo a diferentes escalas y en un acercamiento a la funcionalidad práctica y simbólica de un conjunto de objetos que clasificamos dentro de un estilo. Estas líneas de trabajo se amplían con la comparación del conjunto delimitado frente a otros conjuntos: otros estilos cerámicos contemporáneos, previos o posteriores y elaboraciones en otros materiales como textiles, objetos de metal, madera, etc. La integración de estos aspectos nos ayuda a comprender el rol social de dicha categoría artefactual en diferentes momentos de la historia de la sociedad que los produjo?

En segundo término, es importante aclarar que la contextualización temporal mediante el tratamiento de datos radiocarbónicos que presentamos está basada en información generada por varios equipos de investigación, de acuerdo con sus objetivos particulares. En total, fueron considerados 47 fechados radiocarbónicos de contextos publicados con alfarería Famabalasto Negro Grabado. Si bien la mayoría (26) son también del poblado de Rincón Chico, aquí se reunieron 21 fechados de otras ocho localidades arqueológicas, por lo que las tendencias observadas trascienden el ámbito de un poblado singular, obteniéndose pautas regionales para la cronología del estilo. En tal sentido puede ser considerado un ejercicio "económico" que se propone sacar provecho de la síntesis de un importante conjunto de datos disponibles en la bibliografía.

A esta compilación de datos, sumamos los resultados de una excavación estratigráfica en área extendida (Barker 1977), específicamente orientada a nuestro objetivo actual. Las excavaciones programadas se realizaron en el sitio o conjunto arquitectónico RCh18 ubicado en el sector bajo del poblado tardío de Rincón Chico, en el valle de Yocavil. Se excavó allí un recinto circular completo de 28 $\mathrm{m}^{2}$ de superficie interna, con el propósito de ampliar los elementos de análisis que permitieran evaluar de manera crítica dos fechados radiocarbónicos obtenidos en base a materiales recuperados en excavaciones previas - del

7 Los resultados de este panorama global para el estilo Famabalasto Negro Grabado se presentan en Palamarczuk (2011). 
año 1988 - en el cuadrante SW de esa misma estructura (890 \pm 100 AP [LP 428] y $1020 \pm 90$ AP [LP 471]). Esos fechados son, hasta el momento, los más tempranos para contextos con cerámica FNG y fueron empleados para sustentar la idea de una mayor profundidad temporal del estilo dentro del período Tardío (Tarragó 1995; Palamarczuk y Manasiewicz 2009 [2001]).

Tanto para el NOA, como para la región andina en general, los estilos alfareros fueron definidos y ordenados en secuencias cronológicas con anterioridad al desarrollo de métodos absolutos. Recientes revisiones de algunas asignaciones temporales se han llevado adelante mediante dataciones directas por termoluminiscencia (por ejemplo, Schiappacasse et al. 1991; Uribe 2002; De La Fuente et al. 2010) y/o el fechamiento por radiocarbono de áreas domésticas y del material fragmentario allí encontrado (Nielsen 1997; Bauer 2002; Zeidler 2003, por citar algunos ejemplos en los Andes). En tal caso, consideramos necesario establecer criterios de evaluación de las asociaciones para obtener el mayor provecho de la compilación de largas series de datos y listas de fechados, aunque esto implique la exclusión de algunos de los mismos (Pettit et al. 2003; Nolan 2011). Tomando en cuenta estos antecedentes, el análisis cronológico se basa en la propuesta metodológica aplicada por uno de nosotros para el estudio crítico de los fechados radiocarbónicos y la cronología cerámica del poblado de Rincón Chico (Greco 2007).

La metodología evalúa la asociación entre los fechados radiocarbónicos, los eventos a datar (por ejemplo, estructuras de combustión, pisos o sepulcros) y, a su vez, los niveles de asociación entre los conjuntos cerámicos y los contextos fechados. Una de las precauciones a tener en cuenta para el análisis es que no todos los fechados están igualmente asociados a los eventos que se pretendía datar (Figini 2004). Por tal motivo, se determinaron diferentes grados de certeza en la asociación muestra-evento según la escala que se detalla a continuación (Waterbolk 1983; Carbonari 1994).

a. Completamente cierta: cuando la muestra y el evento constituyen el mismo objeto arqueológico. Por ejemplo, artefacto de madera o restos óseos articulados de un entierro.

b. Altamente probable: cuando existe una relación funcional directa entre el material orgánico (muestra) y los hallazgos arqueológicos diagnósticos. Por ejemplo, fogón en el piso de una habitación, resto de comida dentro de un recipiente, resto carbonizado en el hornillo de una pipa.

c. Probable: cuando no hay una relación funcional demostrable, pero la cantidad y el tamaño de los fragmentos de material orgánico argumentan a favor de su asociación. Por ejemplo, concentración de carbones o fragmentos óseos en un piso de ocupación.

d. Poco probable: partículas de carbón pequeñas y esparcidas en la matriz sedimentaria que contiene materiales arqueológicos.

Sobre la base de un planteo similar, se discrimina la asociación entre los eventos datados (como fogones o pisos) con los conjuntos cerámicos recuperados y en particular con los fragmentos FNG que son objeto del estudio. Así se trabajó con otra escala cuatripartita de asociación fechado-cerámica.

i. Altamente probable: Cuando hay una relación funcional directa entre la cerámica (en este caso FNG) y el evento fechado. Por ejemplo, vasija conteniendo un enterratorio, con evidencias de uso sobre un fogón datado o con contenido orgánico.

ii. Probable: Alto grado de remontaje en las vasijas o alto nivel de agrupamiento en familias de fragmentos sensu Orton et al. (1997), asociados a un piso de ocupación. Por ejemplo, grandes cantidades de fragmentos cerámicos sin remontaje o agrupación, pero distribuidos en áreas de descarte-producción.

iii. Poco probable: Fragmentos cerámicos dispersos en la matriz sedimentaria, o incluso por sobre un piso de ocupación, pero en escasa cantidad y bajo grado de remontaje o agrupación en familias de fragmentos.

iv. Inexistente: No hay cerámica asociada al evento datado o la presencia es mínima.

Tomando en cuenta estas escalas de asociación, muestraevento por un lado y fechado-cerámica por el otro, se evaluaron entonces los resultados radiocarbónicos conocidos para contextos con cerámica FNG. Estos grados de 
asociación no son absolutos ni rígidos, sino que deben ser evaluados en cada caso de acuerdo a múltiples variables particulares como estratigrafía, superficie excavada, integridad de los conjuntos cerámicos, etc. Incluso más, esto será dependiente del conjunto cerámico que estemos considerando, ya que se encontraron varios casos en donde la asociación fechado-cerámica es buena desde una perspectiva general, pero atendiendo a la cerámica FNG en particular, el nivel de confianza podría disminuir al presentarse esta en escasa proporción.

Asimismo, se observa la composición estilística y las relaciones cuantitativas de las cerámicas que integran dichos conjuntos, puesto que el conocimiento acerca de la cronología de los estilos asociados es otro dato que se pone en juego para la evaluación de la temporalidad del Famabalasto Negro Grabado.

Este análisis de asociaciones nos permite evaluar la cronología de la disposición final de las cerámicas. La perspectiva de la historia de vida de los objetos sensu Appadurai (1991 [1986]) aporta una necesaria precaución, si tenemos en cuenta que algunos objetos pudieron tener una vida útil extensa y cambiante. En tal sentido, la consideración de una muestra integrada por numerosos casos es una estrategia adecuada para dar cuenta de múltiples situaciones de desempeño, delineando un rango cronológico de la vigencia del estilo. Por esta razón, aceptamos que no existe entre los fechados radiocarbónicos y la cerámica una asociación completamente cierta, ya que siempre mediará un lapso de tiempo indeterminado entre la confección de las mismas y sus usos.

\section{* AnÁlisis de CAsos}

Se describen brevemente un total de 47 casos con fechados radiocarbónicos en nueve localidades arqueológicas (seis en Yocavil, una en el valle Calchaquí, una en Andalgalá y una en Hualfín). La información referida a las localidades de Angastaco (valle Calchaquí), Tolombón, El Pichao y Los Cardones (Yocavil), Potrero Chaquiago (Andalgalá) y Loma de los Antiguos (Hualfín) surge del trabajo de diferentes equipos de investigación y aquí se emplean los datos disponibles en la bibliografía. Las investigaciones en Las Mojarras, Rincón Chico, Loma Rica de Shiquimil y El Calvario de Fuerte Quemado (Yocavil) fueron desarrolladas por el grupo de investigación Yocavil. ${ }^{8}$ Mientras que los sitios Angastaco y Potrero Chaquiago corresponden a instalaciones incaicas, todas las otras localizaciones consideradas son centros poblados aglomerados del período Tardío, que también presentan evidencias de ocupaciones posteriores. A continuación, se presentarán de manera sucinta los sitios que cuentan con fechados radiocarbónicos vinculados a fragmentos o vasijas Famabalasto Negro Grabado (Tabla 1).

Los criterios de cuantificación (conteo de fragmentos, número mínimo de vasijas y familias de fragmentos) son variables de acuerdo con la fuente consultada. Para facilitar la comparación de las frecuencias cerámicas entre contextos, hemos reunido la información cuantitativa disponible generada por el grupo de investigación Yocavil en la Tabla 2. Los sitios sin información sobre frecuencias cerámicas o que se basan en diferentes categorías tipológicas no se incluyeron en la tabla y la información se presenta redactada en los respectivos párrafos.

\section{Valle Calchaquí}

Angastaco. Ubicado en el sector medio del valle Calchaquí, el sitio Pukara de Angastaco y su tambo se definieron, tanto por su arquitectura, materiales presentes y datos históricos, como del período Inca. Los fechados radiocarbónicos asociados a cerámica FNG proceden de distintas excavaciones en el tambo. Por un lado, de un área de descarte en el límite del tambo se obtuvo carbón vegetal que fue datado en $530 \pm 40 \mathrm{AP}$ (Beta 203739), fragmentos cerámicos con decoración inca, y escasos fragmentos $\mathrm{Pa}$ cajes, Santa María Bicolor, Famabalasto Negro Grabado y no decorado (Cremonte y Williams 2007: 221). Por otro lado, otros tres casos de eventos de combustión fueron fechados en $300 \pm 60$ AP (Beta 239859), 420 \pm 60 AP (Beta 239860) y $570 \pm 70 \mathrm{AP}$ (Beta 239861), los dos últimos en áreas de recintos, aunque no se han publicado todavía mayores detalles al respecto (Williams 2010). La cuantificación total muestra presencia minoritaria de Famabalasto Negro Grabado y cerámica incaica y santamariana

8 Desde 1986 se desarrollan trabajos en diferentes sitios del área centro y sur de Yocavil, en proyectos dirigidos por la Dra. Myriam Tarragó en varios de los cuales han participado los autores de este trabajo. 
Valeria Palamarczuk, Catriel Greco

\begin{tabular}{|c|c|c|c|c|c|c|c|}
\hline Cód. Lab. & $\begin{array}{l}\text { Años } \\
\text { C14 AP }\end{array}$ & Sitio & $\begin{array}{c}\text { Sector/ } \\
\text { Estructura }\end{array}$ & Origen de la muestra & $\begin{array}{c}\text { Asoc. } \\
\text { Muestra- } \\
\text { Evento }\end{array}$ & $\begin{array}{l}\text { Asoc. } \\
\text { Fechado- } \\
\text { Cerámica }\end{array}$ & Referencia \\
\hline LP 976 & moderno & $\begin{array}{l}\text { Loma de Los } \\
\text { Antiguos }\end{array}$ & Recinto 11 & Carbón vegetal disperso, nivel $60 \mathrm{~cm}$ & C & II & Wynveldt 2009 \\
\hline LP 1009 & moderno & Rincón Chico & $\mathrm{RCh}_{15}-\mathrm{MM}$ & $\begin{array}{l}\text { Estructura de combustión } \\
\text { asociada a actividades pirotecnológicas }\end{array}$ & B & III o IV & Greco 2007 \\
\hline LP 1021 & $210 \pm 60$ & Rincón Chico & $\mathrm{RCh}_{15}-\mathrm{MM}$ & $\begin{array}{l}\text { Estructura de combustión } \\
\text { asociada a actividades pirotecnológicas }\end{array}$ & B & III o IV & Tarragó 2007 \\
\hline Beta 162380 & $240 \pm 40$ & Rincón Chico & $\begin{array}{c}\text { RCh } 1-\text { Sector XIII } \\
- \text { ML }_{39}\end{array}$ & Entierro de subadulto en una urna funeraria & B & III & $\begin{array}{l}\text { González y Tarragó 2005; } \\
\text { Greco } 2007\end{array}$ \\
\hline Beta 239859 & $300 \pm 60$ & Angastaco & Tambo & $\begin{array}{l}\text { "cuadrícula del sector del límite suroriental" } \\
\text { (Williams 2010:94) }\end{array}$ & $?$ & $?$ & Williams 2010 \\
\hline LP 1350 & $310 \pm 60$ & Rincón Chico & $\begin{array}{l}\text { RCh } 1 \text { - Sector VIII } \\
- \text { ML }_{7}\end{array}$ & Carbones concentrados sobre el piso del recinto & $\mathrm{C}$ & III o IV & $\begin{array}{l}\text { González y Tarragó 2005; } \\
\text { Greco } 2007\end{array}$ \\
\hline LP 1903 & $340 \pm 50$ & $\begin{array}{l}\text { El Calvario de } \\
\text { Fuerte Quemado }\end{array}$ & $\begin{array}{l}\text { Sector III, Torreón } \\
\text { Superior }\end{array}$ & Carbones incluidos en piso limo arcilloso preparado & $\mathrm{C}$ & II & - \\
\hline LP 1644 & $350 \pm 50$ & $\begin{array}{l}\text { Loma de Los } \\
\text { Antiguos }\end{array}$ & Recinto 31 & Entierro humano en recinto habitacional & A & III & Wynveldt 2009 \\
\hline GX 29663 & $350 \pm 60$ & Tolombón & $\mathrm{T}_{2} \mathrm{~A} 6 \mathrm{c} 5 \mathrm{n} 6 \mathrm{~L} 1$ & Carbones de fogón? & B? & II & Williams 2003, 2010 \\
\hline LP 1310 & $400 \pm 60$ & Las Mojarras & $\begin{array}{l}\text { Las Mojarras 1- } \\
\text { Augier }\end{array}$ & Concentración de semillas de maíz carbonizadas & B & IV & $\begin{array}{l}\text { González y Tarragó 2005; } \\
\text { Pratolongo 2008 }\end{array}$ \\
\hline Beta 239860 & $420 \pm 60$ & Angastaco & Tambo & "carbón de un nivel del recinto 1" (Williams 2010:94) & $?$ & $?$ & Williams 2010 \\
\hline LP 1015 & $430 \pm 60$ & Rincón Chico & RCh $14-E_{1}$ & $\begin{array}{l}\text { Fogón delimitado por tres piedras } \\
\text { clavadas, en el piso del recinto }\end{array}$ & B & II & $\begin{array}{l}\text { González y Tarragó 2005; } \\
\text { Palamarczuk 2008 }\end{array}$ \\
\hline Beta 168672 & $440 \pm 50$ & Tolombón & $\mathrm{T} 2 \mathrm{~A} 6 \mathrm{c} 3 \mathrm{n} 7$ & Carbones de fogón? & B? & II & Williams 2003, 2010 \\
\hline sin datos & $440 \pm 60$ & Tolombón & $\begin{array}{l}\text { Sector Conoide, } \\
\text { Div.Arq. D, } \\
\text { Recinto A }\end{array}$ & Carbones sobre el piso? & $?$ & II & Williams 2003 \\
\hline Beta 171426 & $440 \pm 60$ & Tolombón & T2A6c6n9 & Lente de ceniza y carbón por debajo del piso? & $\mathrm{B} \circ \mathrm{C}$ & II & Williams 2003, 2010 \\
\hline LP 1484 & $460 \pm 60$ & Los Cardones & $\begin{array}{l}\text { Sector } 5 \text { R7 } 8- \\
\text { Nivel } 1 \text { ( } 0-20 \mathrm{~cm})\end{array}$ & ¿? & $?$ & II & Rivolta y Salazar 2006 \\
\hline Beta 171425 & $460 \pm 60$ & Tolombón & T2A6c6n6 & Carbones de fogón? & $\mathrm{B}$ ? & II & Williams 2003, 2010 \\
\hline LP 2212 & $460 \pm 80$ & $\begin{array}{l}\text { Loma Rica de } \\
\text { Shiquimil }\end{array}$ & Sector A - R27 & Carbones concentrados sobre el piso del recinto & $\mathrm{C}$ & III & Greco 2012 \\
\hline LP 319 & $480 \pm 50$ & Potrero Chaquiago & $\begin{array}{l}\text { La Solana RIII, } \\
\text { Cuad. IV, N9 }\end{array}$ & Tronco-poste quemado & $\mathrm{C}$ & II & Williams 1995 \\
\hline LP 2225 & $480 \pm 50$ & Rincón Chico & RCh 15 -AN & $\begin{array}{l}\text { Estructura de combustión } \\
\text { asociada a actividades pirotecnológicas }\end{array}$ & B & II & Marchegiani 2011 \\
\hline Beta 130222 & $490 \pm 50$ & Rincón Chico & RCh 12 - E1 & Fogón delimitado por piedras, en el piso del recinto & B & II & $\begin{array}{l}\text { González y Tarragó 2005; } \\
\text { Palamarczuk 2008 }\end{array}$ \\
\hline LP 713 & $500 \pm 60$ & Rincón Chico & $\mathrm{RCh}_{15}-\mathrm{MO}$ & $\begin{array}{l}\text { Estructura de combustión } \\
\text { asociada a actividades pirotecnológicas }\end{array}$ & B & II & Tarragó 2007 \\
\hline GX 29251 & $500 \pm 60$ & Tolombón & $\mathrm{T}_{2} \mathrm{~A} 6 \mathrm{c} 3 \mathrm{n} 6$ & Carbones de fogón? & B? & II & Williams 2003, 2010 \\
\hline LP 1624 & $520 \pm 50$ & Rincón Chico & $\mathrm{RCh} 8-\mathrm{E}_{2}$ & Fogón en el piso del recinto & B & II & Greco 2007 \\
\hline Beta 203739 & $530 \pm 40$ & Angastaco & Tambo & Carbón vegetal de un área de descarte & $?$ & III & $\begin{array}{c}\text { Cremontey Williams 2007 } \\
\text { Williams 2010 }\end{array}$ \\
\hline LP 1638 & $550 \pm 50$ & Rincón Chico & RCh 1 - Sector I - E6 & $\begin{array}{l}\text { Lente de cenizas y carbón, } \\
\text { sin asoc. a una superficie de ocupación }\end{array}$ & C & II o III & Reynoso 2006 \\
\hline Beta 131674 & $560 \pm 60$ & Rincón Chico & $\mathrm{RCh}_{13}-\mathrm{E}_{1}$ & $\begin{array}{l}\text { Estructura de combustión } \\
\text { asociada a actividades pirotecnológicas }\end{array}$ & B & III & $\begin{array}{c}\text { González y Tarragó 2005; } \\
\text { Palamarczuk 2008 }\end{array}$ \\
\hline Beta 49616 & $560 \pm 70$ & Potrero Chaquiago & $\begin{array}{l}\text { La Solana RIII, } \\
\text { Cuad.I, N6 }\end{array}$ & Maiz carbonizado de un fogón & B & II & Williams 1995 \\
\hline LP 1622 & $570 \pm 60$ & Rincón Chico & $\begin{array}{c}\text { RCh } 1 \text { - Sector VIII } \\
- \text { E } 128^{-128}\end{array}$ & Fogón en el piso del recinto & B & III o IV & Greco 2007 \\
\hline $\mathrm{LP}_{728}$ & $570 \pm 60$ & Rincón Chico & $\mathrm{RCh}_{15}-\mathrm{MO}$ & $\begin{array}{l}\text { Estructura de combustión } \\
\text { asociada a actividades pirotecnológicas }\end{array}$ & B & II & Tarragó 2007 \\
\hline LP 1573 & $570 \pm 60$ & Los Cardones & $\begin{array}{l}\text { Sector 6 R81- } \\
\text { Nivel 20-60cm } \\
\end{array}$ & Concentración de carbones en relleno & CoD & II & Rivolta y Salazar 2006 \\
\hline Beta 239861 & $570 \pm 70$ & Angastaco & Tambo & "carbón de un nivel del recinto 2" (Williams 2010:94) & $?$ & $?$ & Williams 2010 \\
\hline LP 2208 & $620 \pm 70$ & Rincón Chico & RCh 15 -AN & $\begin{array}{l}\text { Estructura de combustión } \\
\text { asociada a actividades pirotecnológicas }\end{array}$ & B & II & Marchegiani 2011 \\
\hline LP 1461 & $650 \pm 60$ & Rincón Chico & $\mathrm{RCh}_{15}-\mathrm{MO}$ & $\begin{array}{l}\text { Estructura de combustión } \\
\text { asociada a actividades pirotecnológicas }\end{array}$ & B & II & Tarragó 2007 \\
\hline $\mathrm{LP}_{4} \mathrm{O} 1$ & $660 \pm 70$ & Rincón Chico & $\mathrm{RCh}_{15}-\mathrm{MO}$ & $\begin{array}{c}\text { Estructura de combustión } \\
\text { asociada a actividades pirotecnológicas }\end{array}$ & B & II & Tarragó 2007 \\
\hline LP 1491 & $660 \pm 70$ & Rincón Chico & $\mathrm{RCh} 8-\mathrm{E}_{2}$ & Carbones concentrados sobre el piso del recinto & $\mathrm{C}$ & II & Greco 2007 \\
\hline $\mathrm{LP}_{416}$ & $680 \pm 110$ & Rincón Chico & $\mathrm{RCh}_{15}-\mathrm{E}_{1}$ & Fogón en cubeta en el piso del recinto & B & III o IV & Tarragó 2007 \\
\hline LP 1636 & $690 \pm 70$ & Rincón Chico & RCh 1 -Sector I-E6 & $\begin{array}{l}\text { Lente de cenizas y carbón, } \\
\text { sin asoc. a una superficie de ocupación }\end{array}$ & C & II o III & Reynoso 2006 \\
\hline LP 771 & $720 \pm 60$ & Rincón Chico & $\begin{array}{l}\text { RCh 1-Sector } \\
\text { IX E161 }\end{array}$ & Fogón en el piso del recinto & B & III & Greco 2007 \\
\hline GX 29252 & $720 \pm 60$ & Tolombón & $\mathrm{T}_{2} \mathrm{~A} 6 \mathrm{c} 3 \mathrm{n} 1 \mathrm{O}$ & Lente de ceniza y carbón por debajo del piso? & $\mathrm{B} \circ \mathrm{C}$ & II & Williams 2003, 2010 \\
\hline $\mathrm{LP}_{451}$ & $820 \pm 80$ & Rincón Chico & $\mathrm{RCh}_{15}-\mathrm{E}_{3}$ & Fogón en el piso del recinto & B & III o IV & Tarragó 2007 \\
\hline LP 1414 & $830 \pm 60$ & Rincón Chico & $\begin{array}{l}\text { RCh } 1 \text { - Sector } \\
\quad \mathrm{X}-\mathrm{E} 214\end{array}$ & Fogón en el piso del recinto & B & III & López y Spano 2006 \\
\hline LP 459 & $830 \pm 90$ & Rincón Chico & $\mathrm{RCh}_{15}-\mathrm{E}_{2}$ & Carbones concentrados sobre el piso del recinto & $\mathrm{C}$ & III o IV & Tarragó 2007 \\
\hline LP 428 & $890 \pm 100$ & Rincón Chico & $\mathrm{RCh}_{18}$ - E2 & Carbones concentrados en el sedimento de relleno & $\mathrm{D}$ & II & Tarragó 1995; Greco 2007 \\
\hline LP 1495 & $930 \pm 70$ & Los Cardones & $\begin{array}{l}\text { Sector } 5 \text { R78 } \\
\text {-Nivel } 4 \\
(60-80 \mathrm{om})\end{array}$ & ? & ? & III & Rivolta y Salazar 2006 \\
\hline LP 471 & $1020 \pm 90$ & Rincón Chico & $\mathrm{RCh}_{1} 8-\mathrm{E}_{2}$ & Carbones dispersos sobre el piso del recinto & $\mathrm{C}$ & II & Tarragó 1995; Greco 2007 \\
\hline LP 529 & $1175 \pm 70$ & Rincón Chico & $\mathrm{RCh}_{15}-\mathrm{E}_{1}$ & $\begin{array}{l}\text { Carbones concentrados sobre el piso del recinto, } \\
\text { en torno al fogón en cubeta (fechado LP 416) }\end{array}$ & C & III o IV & Tarragó 2007 \\
\hline
\end{tabular}

Tabla 1. Fechados radiocarbónicos asociados a cerámica Famabalasto Negro Grabado. 
en proporciones cercanas al 30\% (Cremonte et al. 2010: 1286). Desconocemos cuál era el tipo de concentración de carbón, por lo tanto no se puede establecer el grado de asociación muestra-evento.

\section{Andalgalá}

Potrero Chaquiago. Gracias a las excavaciones en esta localidad, se realizaron 10 fechados radiocarbónicos (Williams 1995: 213-214), aunque solo se consideran en esta oportunidad dos realizados en el Recinto III del sector La Solana, en el que se hallaron fragmentos FNG. ${ }^{9}$ Los abundantes hallazgos cerámicos en esa estructura alcanzaron un total de 20.249 fragmentos que fueron clasificados como: $24,2 \%$ inca provincial; $2,6 \%$ inca local; $47,7 \%$ material no decorado; $10 \%$ ollas pie de compotera con rastros de hollín; y 15,2\% material fase inca. La cerámica de la fase inca incluye los estilos Santa María, Belén, Yavi Chico, Yocavil Polícromo y Famabalasto Negro sobre Rojo. De un total de 3.170 fragmentos fase inca, el 95,74\% corresponde al Famabalasto Negro sobre Rojo. Los estilos Inca Negro Pulido e Inca Negro Pulido e Inciso (equivalente del FNG) se incluyeron en la categoría inca provincial. De los 4.975 inca provincial, solo el 1,99\% corresponde al grupo de los Negro Pulidos tomados en conjunto (Williams 1995: Cuadro 16 y 18).

El fechado de 560 $\pm 70 \mathrm{AP}$ (Beta 49616) proviene del cuadrante 1 , nivel 6 y se obtuvo a partir de un hallazgo de marlos de maíz carbonizados asociados a una estructura de combustión y el grado de asociación muestra-evento se considera entonces como altamente probable. El fechado de $480 \pm 50 \mathrm{AP}$ (LP 319) procede del cuadrante IV, nivel 9 donde se obtuvo un tronco carbonizado del cual se tomó una rodaja como muestra a datar. El tronco se encontró rodeado por tres piedras y se interpretó como los restos de un poste de un techado precario o bien de un telar (Williams 1995: 213-214). La definición del grado de asociación muestra-evento se plantea especialmente complejo en este caso, dadas las dificultades para relacionar cronológicamente los postes y los pisos de ocupación, además de los problemas de longevidad y durabilidad de la madera posiblemente utilizada como poste (Marconetto 2007). Se considera entonces una asociación muestra-evento de tipo $\mathrm{C}$, probable.

9 Denominado como "Inca negro pulido e inciso" por Williams (1995).
La asociación fechados-fragmentos cerámicos se considera como de tipo II, probable, dado que si bien en términos comparativos los hallazgos FNG son muy escasos, varios de ellos proceden de los niveles 6 e inferiores y se pudieron practicar algunos remontajes.

\section{Hualfín}

Loma de los Antiguos de Azampay. Wynveldt (2009) informa un fechado para el Recinto 11 de este poblado tardío. El mismo se realizó sobre carbón vegetal que se encontró disperso en el nivel más profundo (de $60 \mathrm{~cm}$ ), por lo tanto se considera que tiene un grado $\mathrm{C}$ de asociación muestra-evento. El resultado de la datación fue "moderno" (LP 976). En esta excavación se recuperó un puco Famabalasto Negro Grabado y un puco Belén fragmentados pero muy completos, una pieza doméstica y restos de un puco y una tinaja indeterminados.

Asimismo, excavaciones en el Recinto 31 revelaron la existencia de un posible fogón circular frente a la entrada, un hoyo de poste central, y un posible pozo de almacenaje en el ángulo norte. El conjunto cerámico vinculado al piso incluye los fragmentos de varias vasijas incompletas: cuatro tinajas, dos pucos y una ollita Belén, un puco Famabalasto Negro Grabado y una vasija Ordinaria. En el ángulo sur del recinto se excavó la sepultura de una mujer madura colocada en posición genupectoral, sobre su lado derecho, mirando al oeste y sin su cráneo, con una tinaja Belén como acompañamiento funerario. A partir de los restos óseos, se obtuvo la fecha de $350 \pm 50 \mathrm{AP}$ (LP-1644). El entierro habría ocurrido con posterioridad al empleo doméstico del recinto, pudiendo los materiales hallados sobre el piso corresponder a usos previos de la estructura (Wynveldt 2009). A los fines de nuestro análisis, se considera que la asociación entre el fechado y la cerámica FNG vinculada al piso es poco probable.

\section{Valle de Yocavil}

Tolombón. Sector Conoide, División arquitectónica D, Recinto $A$. El Sector Conoide constituye el núcleo residencial del poblado de Tolombón. Del sondeo del Recinto A, una estructura circular deprimida de $2,50 \mathrm{~m}$ de circunferencia, se obtuvo una rara vasija antropomorfa con aplicaciones al pastillaje y dibujos en negro sobre 


\begin{tabular}{|c|c|c|c|c|c|c|c|c|c|c|c|c|c|c|c|}
\hline Sitio & Estilo & 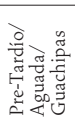 & 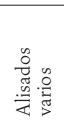 & $\frac{. \bar{\Xi}}{\check{\varpi}}$ & 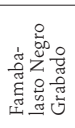 & 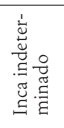 &  & 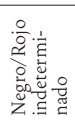 & 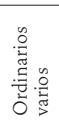 & 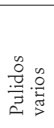 & 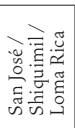 & 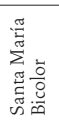 & 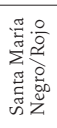 & 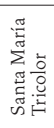 & 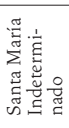 \\
\hline \multirow{2}{*}{ CFQ-TSUP } & $\%$ Frag. $(N=105)$ & & 1,9 & & 8,6 & & 1,9 & 14,3 & 42,9 & 1,0 & & 27,6 & & 1,0 & 1,0 \\
\hline & $\% \mathrm{FF}(\mathrm{N}=75)$ & & 2,7 & & 2,7 & & 2,7 & 18,7 & 38,7 & 1,3 & & 30,7 & & 1,3 & 1,3 \\
\hline \multirow{2}{*}{ LM 1 - Augier } & \% Frag. $(\mathrm{N}=768)$ & 2,6 & 5,9 & 0,1 & 6,9 & 0,4 & 7,0 & 1,6 & 43,8 & 0,9 & 8,6 & 2,9 & 1,4 & 0,4 & 17,6 \\
\hline & $\% \mathrm{FF}(\mathrm{N}=551)$ & 3,5 & 6,0 & 0,2 & 3,1 & 0,5 & 8,4 & 1,8 & 45,6 & 1,3 & 8,5 & 2,4 & 1,3 & 0,5 & 17,0 \\
\hline LRS - R27 & $\%$ Frag. $(N=224)$ & & 0,5 & & 0,9 & & 32,1 & 13,4 & 26,8 & & 14,7 & 0,5 & & 3,1 & 8,0 \\
\hline \multirow{2}{*}{$\mathrm{RCH}_{1}-\mathrm{E} 6$} & \% Frag. $(\mathrm{N}=16)$ & & & & 5,9 & & & & 94,1 & & & & & & \\
\hline & $\% \mathrm{FF}(\mathrm{N}=2)$ & & & & 50,0 & & & & 50,0 & & & & & & \\
\hline \multirow{2}{*}{$\mathrm{RCH}_{1}-\mathrm{ML}_{7}$} & $\%$ Frag. $(\mathrm{N}=9)$ & & & 22,2 & 11,1 & & & & & & & & & & 66,7 \\
\hline & $\% \mathrm{FF}(\mathrm{N}=6)$ & & & 16,7 & 16,7 & & & & & & & & & & 66,6 \\
\hline \multirow{2}{*}{$\mathrm{RCH}_{1-128}$} & \% Frag. $(\mathrm{N}=14)$ & & & & 7,1 & & 35,8 & & 7,1 & 14,2 & & & & & 35,8 \\
\hline & $\% \mathrm{FF}(\mathrm{N}=13)$ & & & & 7,7 & & 30,8 & & 7,7 & 15,4 & & & & & 38,4 \\
\hline \multirow{2}{*}{$\mathrm{RCH}_{1}-\mathrm{ML}_{39}$} & \% Frag. $(\mathrm{N}=109)$ & & & & 0,9 & & 3,7 & & & & & 95,4 & & & \\
\hline & $\% \mathrm{FF}(\mathrm{N}=4)$ & & & & 25,0 & & 25,0 & & & & & 50,0 & & & \\
\hline \multirow{2}{*}{$\mathrm{RCH}_{1}-\mathrm{E}_{1} 6_{1}$} & \% Frag. $(\mathrm{N}=39)$ & & & & 2,6 & & & & 94,8 & & & & & & 2,6 \\
\hline & $\% \mathrm{FF}(\mathrm{N}=4)$ & & & & 25,0 & & & & 50,0 & & & & & & 25,0 \\
\hline \multirow{2}{*}{$\mathrm{RCH} 1-\mathrm{E}_{214}$} & \% Frag. $(\mathrm{N}=19)$ & & 36,8 & & 10,5 & & & & 5,3 & & & & 5,3 & 10,5 & 31,6 \\
\hline & $\% \mathrm{FF}(\mathrm{N}=10)$ & & 20,0 & & 20,0 & & & & 10,0 & & & & 10,0 & 10,0 & 30,0 \\
\hline \multirow{2}{*}{$\mathrm{RCH} 8$} & \% Frag. $(N=215)$ & & 0,9 & & 13,0 & & 1,9 & & 12,1 & & & 23,3 & & 27,4 & 21,4 \\
\hline & $\% \mathrm{FF}(\mathrm{N}=42)$ & & 2,4 & & 16,7 & & 7,1 & & 23,8 & & & 7,1 & & 14,3 & 28,6 \\
\hline \multirow{2}{*}{$\mathrm{RCH}_{12}$} & $\%$ Frag. $(N=140)$ & & 1,4 & & 6,4 & & 4,3 & & 34,3 & & & 11,4 & 14,3 & & 27,9 \\
\hline & $\% \mathrm{FF}(\mathrm{N}=60)$ & & 1,7 & & 6,7 & & 0,0 & & 35,0 & & & 13,3 & 11,7 & & 31,6 \\
\hline \multirow{2}{*}{$\mathrm{RCH}_{13}$} & $\%$ Frag. $(N=184)$ & & 3,2 & & 78,8 & & 3,3 & & 1,1 & & & 1,6 & & 2,2 & 9,8 \\
\hline & $\% \mathrm{FF}(\mathrm{N}=54)$ & & 9,4 & & 33,3 & & 11,0 & & 3,7 & & & 5,6 & & 3,7 & 33,3 \\
\hline \multirow{2}{*}{$\mathrm{RCH}_{14}$} & $\%$ Frag. $(\mathrm{N}=693)$ & & 0,7 & & 0,6 & 10,7 & 1,6 & & 68,7 & & & 0,4 & 0,4 & & 16,9 \\
\hline & $\% \mathrm{FF}(\mathrm{N}=46)$ & & 8,7 & & 8,7 & 2,2 & 4,3 & & 17,5 & & & 6,5 & 4,3 & & 47,8 \\
\hline \multirow{2}{*}{$\mathrm{RCH}_{15}-\mathrm{MO}$} & $\%$ Frag. $\left(\mathrm{N}=76_{3}\right)$ & & & & 11,5 & & 26,0 & & 22,0 & 0,3 & & 12,6 & 1,6 & & 26,0 \\
\hline & $\% \mathrm{FF}(\mathrm{N}=139)$ & & & & 14,4 & & 9,4 & & 26,7 & 1,4 & & 25,2 & 2,9 & & 20,0 \\
\hline $\mathrm{RCH}_{15}-\mathrm{MM}$ & $\%$ Frag. $(\mathrm{N}=212)$ & & 1,4 & & 0,5 & & 15,0 & & 50,5 & & & 12,3 & 1,9 & 0,5 & 17,9 \\
\hline \multirow{2}{*}{$\mathrm{RCH} 15$ - AN } & $\%$ Frag. $(N=70)$ & & & & 4,3 & & 1,4 & & 32,8 & 1,4 & & 48,5 & 1,4 & & 10,2 \\
\hline & $\% \mathrm{FF}(\mathrm{N}=4 \mathrm{O})$ & & & & 7,5 & & 2,5 & & 27,5 & 2,5 & & 42,5 & 2,5 & & 15,0 \\
\hline $\mathrm{RCH}_{15}-\mathrm{E}_{1}$ & \% Frag. $(\mathrm{N}=\mathbf{2 9})$ & & & & 0,9 & 0,9 & 10,5 & & 33,4 & & & 48,6 & 2,9 & 1,9 & 0,9 \\
\hline \multirow{2}{*}{$\mathrm{RCH}_{15}-\mathrm{E}_{2}$} & \% Frag. $(\mathrm{N}=32)$ & 3,1 & 3,1 & & 3,1 & & 3,1 & & 46,9 & & & 12,5 & 18,8 & & 9,4 \\
\hline & $\% \mathrm{FF}(\mathrm{N}=22)$ & 4,5 & 4,5 & & 4,5 & & 4,5 & & 31,8 & & & 18,3 & 18,3 & & 13,6 \\
\hline $\mathrm{RCH}_{15}-\mathrm{E}_{3}$ & \% Frag. $(\mathrm{N}=52)$ & & & & 1,9 & & & & 69,2 & & & 21,2 & & & 7,7 \\
\hline \multirow{2}{*}{$\mathrm{RCH} 15$ - AN } & \% Frag. $(N=70)$ & & 5,7 & & 4,3 & & 1,4 & & 27,1 & 1,4 & & 48,5 & 1,4 & & 10,2 \\
\hline & $\% \mathrm{FF}(\mathrm{N}=40)$ & & 10,0 & & 7,5 & & 2,5 & & 17,5 & 2,5 & & 42,5 & 2,5 & & 15,0 \\
\hline \multirow{2}{*}{$\mathrm{RCH} 18$} & $\%$ Frag. $(\mathrm{N}=2 \mathrm{O2})$ & & 5,5 & & 20,8 & & & & 12,4 & & & 15,3 & & 16,8 & 29,2 \\
\hline & $\% \mathrm{FF}(\mathrm{N}=51)$ & & 5,9 & & 11,8 & & & & 23,2 & & & 7,8 & & 18,0 & 33,3 \\
\hline
\end{tabular}

Tabla 2. Frecuencias relativas de fragmentos y familias de fragmentos (FF) en diferentes contextos datados de sitios investigados por el Proyecto Arqueológico Yocavil mencionados en el texto: El Calvario de Fuerte Quemado (CFQ), Las Mojarras (LM), Loma Rica de Shiquimil (LRS) y Rincón Chico (RCH). 
baño blanco, completamente cubierta por concreciones que ocultan su diseño. En su interior se encontraron incluidos en sedimentos los restos óseos de un número mínimo de veinte pequeños reptiles Amphisbaena heterozonata. Este hallazgo se interpretó como una introducción antrópica intencional, posiblemente de índole ritual (Kligmann y Albino 2007: 480). La vasija estaba tapada con un puco Famabalasto Negro Grabado partido en dos y se asentaba sobre un piso definido en el nivel 9, fechado en $440 \pm 60 \mathrm{AP}$ (sin datos de laboratório). Recostada sobre la pared noreste, se halló una pequeña vasija ordinaria con superficies tiznadas (Williams 2003: 179-180 y 191). No podemos evaluar el nivel de asociación muestra evento, pero las vasijas estarían asociadas con probabilidad al piso por lo que asignamos tentativamente una asociación probable entre fechado y cerámica.

Tolombón. Sector Base, Recinto 6. Una serie de seis dataciones fueron realizadas sobre muestras procedentes de la excavación de este recinto: $720 \pm 60 \mathrm{AP}$ (nivel 10; GX 29252); $500 \pm 60 \mathrm{AP}$ (nivel 6; GX 29251); $440 \pm 50 \mathrm{AP}$ (nivel 7; Beta 168672); 350 \pm 60 AP (nivel 6; GX 29663); 460 $\pm 60 \mathrm{AP}$ (nivel 6; Beta 171425); 440 $\pm 60 \mathrm{AP}$ (nivel 9; Beta 171426) (Williams 2003: 199-200).

A partir del recuento de un total parcial de 737 fragmentos, se observaron los estilos Famabalasto Negro Grabado, Santamariana negro sobre blanco, Santamariana negro sobre rojo, Santamariano no determinado, Engobe rojo, Yocavil polícromo, Belén, Inca y cerámica no decorada. Entre los niveles 5, 6 y 7 se detectó un fogón de $30 \mathrm{~cm}$ de espesor. El Nivel 7 a su vez constituye un piso de ocupación, aunque se siguió registrando material arqueológico por debajo, y se obtuvieron fechados en los niveles 9 y 10 (Williams 2003: 182-185 y 190-191). No contamos con elementos suficientes como para opinar de manera concluyente con respecto a los grados de asociación muestra-evento, aunque de acuerdo a lo observado en la ilustración de un perfil, todos los fechados corresponderían a fogones o lentes carbonosos, por lo cual de modo tentativo se supone que la asociación es altamente probable o probable.

Debido a la cantidad de fragmentos FNG, a la posibilidad de remontaje y agrupamiento entre grupos de fragmentos afines y a la vinculación con un piso de ocupación, se puede considerar que hay una asociación de grado II, probable, entre las fechas y la cerámica FNG. ${ }^{10}$

El Pichao. Consiste en un extenso poblado con sectores de mayor aglomeración de estructuras y un amplio sistema agrícola con campos de cultivo y andenes. Fue intensamente estudiado por un equipo sueco-argentino, con una gran cantidad de resultados radiocarbónicos y de termoluminiscencia publicados (Cornell y Johansson 1993; Stenborg 2001). Hay al menos cinco casos de fechados asociados con cerámica pulida, que puede corresponder al Famabalasto Negro Grabado, pero el sistema clasificatorio de los autores, ${ }^{11}$ no nos permite evaluarlos de acuerdo a nuestros criterios.

Los Cardones. En distintos recintos excavados del sitio Los Cardones, se ha recuperado cerámica FNG y hay dos casos datados. En el recinto 78 del sector 5 se fechó una muestra de carbón vegetal del nivel o-20 cm en $460 \pm 60$ AP (LP 1484) yotra del nivel de 60-80 cm en 930 $\pm 70 \mathrm{AP}$ (LP 1495) (Rivolta y Salazar 2006). No podemos afirmar cuál es el grado de asociación muestra-evento en cada caso. Un total de 609 tiestos de esta excavación fueron analizados y se calculó un número mínimo de 48 vasijas, de las cuales $9(18,8 \%)$ corresponden a Famabalasto Negro Grabado. Otros tipos representados son el Ordinario Marleado (20,8\%), Santa María Bicolor (22,9\%), BelénQuilmes $(10,4 \%)$ y en proporciones minoritarias Inca Provincial, Ordinario Gris y Ordinario Rojo Liso (Rivolta y Salazar 2006: 99, cuadro 3). Con respecto a la cerámica recuperada, un $81 \%$ de los fragmentos provienen de los niveles superiores, por lo tanto se considera provisionalmente que hay una asociación cerámica-fechado de grado II (probable) para el primer fechado, mientras que para el segundo la asociación podría ser poco probable.

En el recinto 81 del sector 6 , en las proximidades de una gran roca de posible uso ritual, fue fechada en $570 \pm 60 \mathrm{AP}$ (LP 1573) otra muestra de carbones incluidos en el sedimento de relleno por encima del piso, el cual se definió a

\footnotetext{
${ }^{10}$ Se han realizado otros fechados de los cuales no se menciona la asociación artefactual (Williams 2010).

${ }^{11}$ Las clasificaciones fueron hechas en grandes grupos tecnológicos: Mica Ware (MW); Coarse Ware (CW); Brick Red Ware (BR); Polished (Pol). Dentro de este último hay Famabalasto Negro Grabado pero también otros tipos rojos y monocromos pulidos (Stenborg 2001).
} 
$60 \mathrm{~cm}$ de profundidad. La mayor cantidad de fragmentos (más del 60\%) fueron recuperados entre los 40 y $60 \mathrm{~cm}$ de profundidad por sobre el piso de ocupación. Debido a que la muestra de carbones no proviene de un lente o fogón sobre el piso, se podría considerar que el grado de asociación muestra-evento es bajo. En cuanto a la cerámica, fueron recuperados 1382 fragmentos. Se calculó un mínimo de 70 vasijas, contemplando 7 (10\%) Famabalasto Negro Grabado. Los grupos mayoritarios corresponden a Santa María Bicolor $(43,4 \%)$ y Ordinario Rojo Liso (18,8\%). Belén-Quilmes, Inca Provincial, Famabalasto (Negro sobre Rojo), Santa María Tricolor y Ordinario Marleado se cuentan en menores proporciones (Rivolta y Salazar 2006: 98, Cuadro 1). También para este caso y tomando en cuenta la gran cantidad de fragmentos y vasijas, se considera aquí tentativamente un grado de asociación II entre la cerámica y el fechado.

El Calvario de Fuerte Quemado. En este sitio se han realizado hasta el momento excavaciones en tres estructuras circulares (denominadas Torreones Superior, Medio e Inferior) que se emplazan sobre un espolón de la ladera norte del cerro (Sector 3). ${ }^{12}$ Estas construcciones fueron destacadas por los pioneros Methfessel y Quiroga (Quiroga 1901; Raffino 1991), gracias a los cuales se conocen bellas ilustraciones de la integridad de dichas estructuras hacia fines del siglo XIX y comienzos del siglo XX, desmanteladas casi por completo en la actualidad. La evidencia arquitectónica, artefactual y los fechados radiocarbónicos obtenidos hasta el momento apuntan de modo inequívoco al carácter incaico de las mismas.

En el Torreón Superior las excavaciones descubrieron un piso, compuesto por una capa de barro consolidado que se apoyaba sobre una superficie de pequeñas lajas acomodadas, componiendo un empedrado. La cuantificación de la cerámica de todos los niveles de excavación muestra un predominio de estilos tardíos locales, principalmente Santa María Bicolor y Ordinarias peinadas (ver Tabla 2). Las dos familias FNG identificadas estaban contenidas en el sedimento del tercer nivel (relleno), en contacto con la superficie del piso de barro, por lo que es muy probable que se asocien al piso del torreón (Grimoldi et al. 2008 Ms).

\footnotetext{
${ }^{12}$ Están en curso los análisis de los materiales obtenidos en las excavaciones de estas estructuras, lo que permitirá establecer en breve su funcionalidad con mayor certeza.
}

Incluidas en la masa de barro consolidado del piso se observaron espículas dispersas de carbón. En el gabinete se trabajó en el tamizado en seco de la totalidad de ese sedimento para recuperar las espículas, de las cuales se seleccionaron solo las ramitas pequeñas para realizar un fechado, cuyo resultado fue $340 \pm 50 \mathrm{AP}$ (LP 1903). Los carbones se encontraron dispersos pero incrustados en el piso de barro preparado, por lo tanto se considera que tienen un grado $\mathrm{C}$ de asociación muestra-evento. La asociación de las vasijas FNG con el piso datado puede ser considerada como probable (grado II).

Las Mojarras. El único fechado para esta localidad corresponde al montículo Las Mojarras 1 - Augier, donde se realizaron excavaciones de salvataje. Las evidencias sugieren que el lugar formó parte de un área de descarte y de actividades metalúrgicas (González y Tarragó 2005; Pratolongo 2008). En un sondeo en el centro del montículo, se recuperaron abundantes fragmentos, de modalidades similares a los otros sitios del área, aunque se reconocieron también varios de estilos pre tardíos tecnológicamente afines a Aguada o Guachipas, que aparecen en niveles superiores, medios e inferiores. El fechado de $400 \pm 60$ AP (LP 1310) se obtuvo de marlos de maíz quemados procedentes de un fogón que se extiende entre los niveles 17 y 22. A partir de este último, comienzan los niveles arqueológicamente estériles. Se considera que en este caso hay una alta probabilidad de asociación muestra-evento, aumentando la confiabilidad de la fecha por el hecho de haberse realizado sobre vegetales de ciclo vital anual. Sin embargo, por la propia complejidad de los depósitos, situación que está pendiente de estudio, se desconoce cuál es la relación entre este rasgo fechado -el cual pudo ser un pozo relacionado con una probable área de combustión metalúrgica-y los fragmentos cerámicos, los cuales muestran migración vertical evidenciada en el proceso de remontaje. Por lo tanto, se considera que no se puede establecer por el momento relación de ningún tipo entre el fechado y la cerámica.

Loma Rica de Shiquimil. Es un poblado con gran densidad de construcciones ubicado en la cima y laderas de un relicto de terraza. Recientemente, se llevaron a cabo excavaciones exploratorias, en un recinto subcircular de $6 \mathrm{x}$ $4 \mathrm{~m}$ (núm 27), que forma un conjunto con otro similar algo mayor y con una estructura rectangular de $15 \times 8 \mathrm{~m}$. (Greco 2012). Se fechó una concentración de carbones en 
el nivel de $60-70 \mathrm{~cm}$ bajo superficie, cuyo resultado fue $460 \pm 80 \mathrm{AP}$ (LP 2212). Este nivel fue identificado como piso de ocupación, y entendemos que tiene un nivel $\mathrm{C}$ de asociación muestra-evento. ${ }^{13}$

En estas excavaciones se recuperó relativamente gran cantidad de fragmentos en relación al área excavada, sin embargo son muy pequeños y el remontaje es casi nulo, por lo tanto las cuantificaciones fueron realizadas sin agrupar fragmentos y la clasificación estilística resultó muy dificultosa (ver Tabla 2). Aunque la mayoría corresponda a tipos indeterminados, se encontró una buena cantidad de los estilos considerados de inicios del período de Desarrollos Regionales, como Loma Rica, San José, Shiquimil y Santa María Tricolor. Se registraron solo dos fragmentos Famabalasto Negro Grabado, uno casi en superficie y otro por encima del piso. Siendo tan escasa evidencia por el momento, se lo clasifica como un caso de asociación poco probable (III), aunque será muy interesante continuar las investigaciones en este lugar dado que a nivel regional hay poca información sobre las asociaciones entre estos estilos.

Rincón Chico. La localidad está emplazada en el sector medio del Valle de Yocavil. Con una superficie de 500 ha, está compuesta por cerca de 37 sitios o conjuntos constructivos y habría funcionado como un centro poblado de primer orden en la región. Presenta un patrón de asentamiento dividido en tres grandes áreas: a) un poblado conglomerado con un mínimo de 365 estructuras, ubicado sobre el cerro y las laderas de un espolón rocoso de las Sierras del Cajón, denominado $\mathrm{RCh}$ 1; b) 32 conjuntos constructivos a lo largo del conoide aluvional y c) áreas de enterratorios, de circulación y actividades específicas localizadas entre los espacios construidos (Tarragó 1995, 1998, 2007). Para toda la localidad, se cuenta hasta el momento con cuarenta y dos fechados radiocarbónicos, de los cuales veintiséis provienen de excavaciones en donde se recuperaron

${ }^{13}$ Por debajo del piso y los cimientos del recinto, entre los 80-120 $\mathrm{cm}$, se encontró un depósito de arena con gravilla y grava sobre afloramientos del substrato rocoso. No es arqueológicamente estéril ya que se encontraron numerosas astillas óseas y carbón que fue fechado en $500 \pm 60 \mathrm{AP}$ (LP 2431). Este estrato es interpretado como de nivelación previa a la construcción del recinto (Greco 2012). Lo mencionamos aquí por estar relacionado al anterior, aunque no hay cerámica FNG asociada. fragmentos Famabalasto Negro Grabado (ver Tabla 2), que se evalúan a continuación.

Rincón Chico 1. En términos generales, ya sea por el tamaño muy reducido de las excavaciones o por procesos de formación, la cantidad de fragmentos cerámicos recuperados ha sido muy baja en casi todos los casos.

En la plaza de la cumbre en el Sector I (recinto 6 o Plaza Bicolor), se excavó una cuadrícula ubicada hacia el centro, rodeando un gran bloque rosado que marca la división de la estructura de un sector con piedras grisáceas a otro de piedras rosadas. Se obtuvieron dos fechados, $550 \pm 50$ AP (LP 1638) y 690 770 AP (LP 1636), de eventos de combustión, que aunque no se disponen sobre un piso de ocupación, constituyen rasgos discretos que han sido asociados con las actividades de construcción de la plaza. Ambos resultados son estadísticamente indiferenciables (Reynoso 2009).

Se recuperaron 16 fragmentos de una olla con pies Ordinaria peinada con baño blanco, con evidencia de exposición al fuego y uno de un puco FNG. Todos se concentraban en el mismo sector de la estructura de combustión fechada. Siguiendo criterios estratigráficos, sería factible que la cerámica se asocie a el/los eventos de combustión (Reynoso 2009). Sin embargo, el Famabalasto Negro Grabado está representado por apenas un fragmento, lo que disminuye la probabilidad de asociación (Nivel II o III).

Al pie del cerro, en el sector VIII, fue excavado el Megalito 7 , que integra los muros de al menos tres estructuras (González y Doro 2004). La muestra datada proviene de la estructura 139, donde a escasa profundidad desde la superficie se definió un piso. Se obtuvieron fragmentos cerámicos, restos óseos faunísticos y una concentración de carbón vegetal. El fechado de esta concentración fue $310 \pm 60$ AP (LP 1350), tiene un grado C de asociación muestra-evento ("probable"), ya que si bien la muestra provino del piso de ocupación, no conformaba una clara estructura de combustión. La escasa muestra cerámica incluye un fragmento pequeño de puco FNG por lo que no se puede establecer con certeza su vinculación con la ocupación de la estructura ni con el fechado.

En la Estructura 128, ubicada en el mismo sector, se practicó un sondeo gracias al cual se distinguió un piso de 
ocupación con un pequeño fogón y un lente de ceniza. El carbón del fogón fue datado en $570 \pm 60$ AP (LP 1622). Se obtuvieron fragmentos de tamaño muy reducido, lo que no permite adscribirlos en su mayoría más que a formas y estilos indeterminados, por lo que podrían existir más vasijas en los sectores no excavados. Uno de ellos es de un puco FNG. Por lo tanto, la asociación del fechado y la cerámica es por el momento poco probable.

También al pie del cerro, en el sector XIII, se distribuyen una serie de grandes rocas, algunas de las cuales presentan morteros en sus caras y construcciones elípticas de baja altura rodeándolas (González y Doro 2003; González y Tarragó 2005). En la excavación del Megalito 39, se rescataron restos humanos de un adulto y un subadulto, dispersos y en regular estado de conservación debido al derrumbe del pequeño muro circundante y a la escasa profundidad en que se hallaban. Asimismo, se recuperaron numerosos fragmentos de una urna Santa María Bicolor fase V, que pudo ser parcialmente remontada, y de un puco con cuello del mismo estilo. El deterioro de las vasijas es concordante con los procesos sufridos por los restos óseos. Asimismo, la gran cantidad de fragmentos en ambos casos hace pensar que se trata de la urna funeraria y el puco tapa que contenían los restos del párvulo, que fue fechado en $240 \pm 40 \mathrm{AP}$ (Beta 162380), con grado de asociación B. También se halló un fragmento de puco Famabalasto Negro Grabado, pero su presencia no puede ser claramente asociada con el resto de los hallazgos, por lo tanto, si bien Greco (2007) establece un nivel de asociación altamente probable entre el fechado y la cerámica, para el objetivo actual la asociación al FNG es poco probable.

En la Estructura 161, sector IX en zona de ladera, se realizó un sondeo. A una profundidad cercana a los $80 \mathrm{~cm}$ bajo la superficie, se comenzó a definir un piso de sedimento limo arcilloso no muy compacto, de unos $30 \mathrm{~cm}$ de potencia, en cuya parte superior se distinguió un lente de cenizas con carbones y algunos restos óseos faunísticos calcinados. A partir de carbones de la estructura de combustión, se realizó un fechado cuyo resultado fue de $720 \pm 60 \mathrm{AP}$ (LP 771), con un grado B de asociación muestra-evento. Vinculado al piso, se halló un fragmento de puco Famabalasto Negro Grabado y 32 de una misma olla peinada con baño blanco y asas otomorfas. Respecto del primero, no podemos estar seguros de su asociación funcional con el contexto, pudiendo tanto estar presente debido a procesos postdepositacionales, como existir más fragmentos del mismo en los sectores no excavados. El caso de la olla peinada es diferente, ya que la gran cantidad de fragmentos y el remontaje de los mismos, argumentan a favor de su asociación con el contexto (Greco 2007). Al igual que en el Megalito 39, para el presente objetivo, la asociación entre el fechado y el fragmento FNG es poco probable.

Una situación similar encontramos en la Estructura 214 del sector $\mathrm{X}$, también en zona de ladera, aunque aquí el área excavada fue mayor. A una profundidad cercana a los $70 \mathrm{~cm}$ bajo la superficie, se definió un piso sobre el cual se disponían una serie de lentes de ceniza y dos pequeños fogones con carboncillos y ceniza, de donde se obtuvo el fechado de 830 \pm 60 AP (LP 1414), con un grado B de asociación muestra-evento. Entre los artefactos recuperados, se cuenta un hacha de piedra pulida, restos óseos faunísticos y algunas lascas de obsidiana y cuarzo. Salvo en el caso de un gran fragmento de olla peinada con asa otomorfa (López y Spano 2006), la relación funcional del resto de las vasijas es dudosa, debido a que están representadas por fragmentos escasos o únicos. El nivel de asociación es por lo tanto poco probable.

Rincón Chico 8. Emplazado en el sector bajo, cerca del conglomerado RCh 1, el sitio RCh 8 se compone por una estructura trapezoide de $24 \mathrm{~m}$ en su lado mayor, y una circular de $9 \mathrm{~m}$ de diámetro (Tarragó 1998). Éste último fue excavado intra muros en su totalidad. El primer fechado se realizó a partir de carbones de una concentración en el piso asociada a restos óseos faunísticos quemados. El resultado de la medición fue 660 $\pm 70 \mathrm{AP}$ (LP 1491) y tiene un grado $\mathrm{C}$ de asociación muestra-evento. En el sector sureste de la estructura se distinguió un fogón de aproximadamente $80 \mathrm{~cm}^{2}$, con una profundidad máxima de 10 $\mathrm{cm}$ y de allí provino la muestra para un segundo fechado, con un grado B de asociación. Este último arrojó un resultado de 520 $\pm 50 \mathrm{AP}$ (LP 1624). Ambos valores son estadísticamente indiferenciables.

Se reunieron conjuntos cerámicos con alto grado de remontaje, como un puco Santa María Tricolor con decoración interna de dos batracios enfrentados o un gran fragmento de cuello de urna Tricolor fase III. Hay dos pucos Santa María Bicolor: uno de ellos con cuello, que 
se remontó casi íntegro, y otro de borde entrante, del cual se preservó una mitad. Es notable la presencia de un $17 \%$ de vasijas Famabalasto Negro Grabado, uno de los porcentajes más altos registrados. En cuanto a la morfología, se notó un predominio de los cuencos o pucos con un $21,4 \%$ del total de piezas (Baigorria et al. 2005). La asociación de la cerámica con los fechados se considera probable, de grado II.

Rincón Chico 12. Este sitio constituye uno de los conjuntos más marginales con respecto al sitio RCh 1 y se encuentra, junto con los sitios RCh 13, 14 y 15 a la vera de un camino vecinal, fundado con alta probabilidad sobre una antigua traza prehispánica. Se trata de una unidad constructiva con un patrón rectangular orientado nortesur e integrado por un gran recinto de $52 \mathrm{~m}$ de largo y 26 $\mathrm{m}$ de ancho. Este conjunto constructivo se destaca por la presencia de divisiones internas; un muro transversal establece dos sectores denominados respectivamente Sur y Norte. En la unidad de excavación M6, ubicada en el ángulo SE del sector Sur, se definió una superficie de ocupación a una profundidad cercana a $1 \mathrm{~m}$. Se registró una estructura de combustión asociada a la cual se hallaron más de 80 semillas quemadas de maíz, poroto y posiblemente maní y zapallo (González et al. 2002). A partir de carbones de este fogón se obtuvo un fechado de $490 \pm 50$ AP (Beta 130222). Se considera un nivel de asociación muestra evento de grado B (altamente probable).

Se propone, a partir del remontaje y de la agrupación en familias de fragmentos, tomar a los fragmentos de los niveles 5, 6 y 7 como asociados al piso y por lo tanto es ese el material que se considerará vinculado con el fechado, con un buen grado de probabilidad (grado II). Más de la mitad de las vasijas registradas son santamarianas y el estilo Famabalasto Negro Grabado constituye un 6,67\% del conjunto (Palamarczuk 2008).

Rincón Chico 13. Se trata de una unidad constructiva de forma rectangular, de $27 \mathrm{~m}$ de largo, muy afectada por saqueos. En el sector exterior al suroeste de la estructura se excavó la unidad $\mathrm{M}_{2}$, de $4 \mathrm{~m}^{2}$. La excavación reveló superposición de sedimentos cenicientos y rojizos muy compactos y termoalterados, evidenciando una posible área de actividades pirotecnológicas que no se pudo relacionar con claridad a una superficie de piso antiguo. El fechado de 560 $\pm 60 \mathrm{AP}$ (Beta 131674) provino de una estructura de combustión ubicada unos $35 \mathrm{~cm}$ por debajo de la superficie y tiene un grado de asociación muestraevento B. Se consideró a toda la cuadricula como una unidad de análisis (Palamarczuk 2008). Para los fines del presente trabajo se considera que la asociación del FNG con el fechado es poco probable, de grado III.

Rincón Chico 14. Es una unidad constructiva simple de la cual solo se conserva una estructura rectangular de $26 \mathrm{~m}$ de largo pero se han encontrado restos de muros que podrían haber formado parte del conjunto original (Tarragó 1998). En total, se excavó un área de $58 \mathrm{~m}^{2}$ y se detectó una superficie de ocupación definida por una capa de sedimento limo arenoso fino con gravilla, con un área de actividades integrada por una serie de rasgos y artefactos. Entre ellos, se destaca un fogón en cubeta con restos de una vasija calciforme quemada apoyada sobre tres piedras. Otros elementos asociados son dos grandes grupos de fragmentos cerámicos, resultado de la ruptura de tres grandes vasijas Ordinarias peinadas debido al desplome de los muros, una urna santamariana con evidencias de exposición al fuego y una vasija de forma cerrada indistinta, muy fragmentada, pero que corresponde a un estilo incaico indeterminado (probablemente inca provincial o inca mixto). También hay cuatro familias de fragmentos Famabalasto Negro Grabado (Palamarczuk 2008). Asimismo, se definió una amplia área de molienda compuesta por cuatro morteros, un molino plano, una gran laja muy plana y manos de molienda, todo ello dispuesto por encima de una superficie oval de $3 \mathrm{~m}^{2}$ preparada con barro batido. Este contexto se interpretó como un área de producción de alimentos a gran escala, posiblemente chicha, en momentos de influencia incaica (Tarragó et al. 1998-99).

La muestra fechada consiste de un carbón procedente del fogón en cubeta en el piso de ocupación, que se puede considerar con un grado B de asociación muestra-evento. La fecha obtenida fue de $430 \pm 60$ AP (LP 1015). En este caso, resulta más sencillo discriminar aquellas vasijas ligadas por una relación funcional al contexto, debido a la evidencia de rotura in situ y a la escasa perturbación postdepositacional. Consideramos que el fechado tiene una asociación altamente probable con las vasijas tiznadas y representadas por muchos fragmentos, sin embargo, siendo los fragmentos FNG vinculados al piso relativamente escasos, se considera que su asociación al fechado es de grado II o probable. 
Rincón Chico 15. Se trata de una unidad constructiva formada por un cuadrángulo (E1) y dos estructuras anexas de planta irregular (E2 y E3). Considerando la dispersión de restos y rasgos exteriores, el área del sitio fue calculada en una superficie mínima de $5500 \mathrm{~m}^{2}$, de la cual se ha excavado un total de $505,50 \mathrm{~m}^{2}$. En distintos sectores, se registraron actividades de producción (metalúrgica y cerámica) y descarte; también se definieron áreas de actividad doméstica y hacia el norte se encontraron entierros en cámaras sepulcrales (Tarragó 2007).

Del área de descarte y producción denominada Montículo Oriental (MO), se consideran aquí cuatro fechados radiocarbónicos. Si bien se realizaron otros dos, éstos carecen de asociación con materiales específicos. Estas fechas provienen de estructuras de combustión relacionadas a actividades pirotecnológicas que constituyen rasgos netamente definidos y por lo tanto tienen un grado $\mathrm{B}$ de asociación muestra-evento: $500 \pm 60 \mathrm{AP}$ (LP 713); $570 \pm 60$ AP (LP 728); 650 \pm 60 AP (LP 1461) y 660 \pm 70 AP (LP 401). Todas son estadísticamente indiferenciables, pudiéndose promediarlas en $590 \pm 30$ AP. De las distintas excavaciones en el MO, se recuperó gran cantidad de fragmentos de cerámica. Las piezas de tipo Santa María Bicolor y Ordinarias peinadas y/o alisadas son las más abundantes, mientras que el Famabalasto Negro Grabado representa entre un 10 y $15 \%$ del total de los conjuntos.

El Montículo Meridional (MM) es un área de descarte y producción metalúrgica. En este caso, se toman en cuenta solo los datos de la excavación de la unidad U15, que es de donde provienen los dos fechados. Uno de ellos fue realizado a partir de carbones de una compleja estructura de combustión con lentes de ceniza, carbón y sedimentos termoalterados, asociados a actividades de producción metalúrgica, que por lo tanto tienen un grado $\mathrm{B}$ de asociación muestra-evento. El resultado de la datación fue inferior a 200 AP y se informó como "moderno" (LP 1009). El segundo fechado también se realizó en base a carbones provenientes de lentes de ceniza y carbón de una estructura de combustión pirotecnológica. De igual modo, tiene un grado $\mathrm{B}$ de asociación muestra-evento. El resultado de la medición fue $210 \pm 60$ AP (LP 1021). Mientras que Greco (2007) considera que la asociación del conjunto cerámico con los fechados en el MM es buena, para el presente objetivo, la asociación con cerámica FNG solo sería poco probable o inexistente.
En el área norte (AN) del sitio, se encontraron líneas de muro no visibles en superficie y una estructura circular deprimida de paredes de barro interpretada como un horno de producción cerámica (Marchegiani 2011). Se realizaron dos fechados de carbones de rasgos de acumulación de la combustión dentro del horno $(620 \pm 70$ AP (LP 2208) y $480 \pm 50 \mathrm{AP}$ (LP 2225). Ambos tienen un grado de asociación muestra-evento $\mathrm{B}$ y son estadísticamente indiferenciables, pudiendo corresponder a uno o varios eventos de combustión cercanos en el tiempo. La muestra de fragmentos recuperados sobre el piso de la estructura presenta proporciones similares al resto del sitio (Marchegiani 2011) y su asociación con el fechado resulta probable (II).

En cuanto a las tres estructuras del conjunto arquitectónico, se realizaron amplias excavaciones en área, que comparativamente con los casos anteriores, aportaron una cantidad muy baja de cerámica. De un fogón en cubeta en el piso de la Estructura 1, se obtuvo un resultado de 680 \pm 110 AP (LP 416). Un segundo fechado, de $1175 \pm 70 \mathrm{AP}$ (LP 529), provino de carbones concentrados sobre el piso del recinto en torno al mencionado fogón en cubeta. En la Estructura 2, se dataron en $830 \pm 90 \mathrm{AP}$ (LP 459) carbones concentrados sobre el piso del recinto. En la Estructura 3 un fogón en el piso dio una fecha de $820 \pm 80$ AP (LP 451). En cada estructura solo fue recuperado un fragmento Famabalasto Negro Grabado, por lo tanto, si bien Greco (2007) propone distintos grados de asociación entre la cerámica y los fechados, para este ensayo se considera que en estos casos la asociación del FNG es muy baja o inexistente.

Rincón Chico 18. Esta unidad constructiva se compone de un gran recinto rectangular, varias estructuras anexas rectangulares más pequeñas y una circular de 12,5 $\mathrm{m}$ de diámetro, además de líneas de muros poco definidos que conforman otras estructuras (Tarragó 1998). En el año 1988 se excavó el cuadrante suroeste de la estructura circular (R2) y su entrada. Estos trabajos descubrieron un hoyo de poste central y un piso sobre el cual se hallaron espículas de carbón, los fragmentos de un puco Famabalasto Negro Grabado casi completo y medio cuello de una pequeña urna Santa María Bicolor, también muy fragmentado, entre otros tiestos aislados. Con el carbón obtenido se realizaron dos dataciones. El fechado $890 \pm 100 \mathrm{AP}$ (LP 428) se realizó a partir de una 
muestra de carbones concentrados en el sector del vano de acceso del recinto. Un segundo fechado realizado sobre carbones dispersos dio un resultado de $1020 \pm 90$ AP (LP 471).

La asociación del puco FNG a este piso se tomó en cuenta para plantear una posible temporalidad temprana dentro del período de Desarrollos Regionales para el estilo Famabalasto Negro Grabado (Tarragó 1995; Palamarczuk y Manasiewicz 2009 [2001]). La revisión del contexto del R2 de RCh 18 permitió observar que los carbones del primer fechado no provenían de un rasgo de combustión definido, por lo tanto, se consideró un grado D (poco probable) de asociación entre la muestra de carbones y ese piso. Para el segundo, se asignó un grado $\mathrm{C}$ de asociación muestra-evento, ya que provino de carbones dispersos en un área más acotada $\left(2 \mathrm{~m}^{2}\right)$ sobre el piso de ocupación. Ambos fechados son indistinguibles estadísticamente.

Se consideró un grado II de asociación entre la cerámica y los fechados. Sin embargo, en los análisis estadísticos se observó que éstos se apartaban del resto de los obtenidos para esa localidad. Se suma el hecho de que ninguno de estos posee un grado alto de probabilidad de asociación muestra-evento -si bien el puco FNG roto in situ se asocia sin duda al piso del recinto- por lo que se puso en duda la vinculación entre la datación y la cerámica (Greco 2007). Más adelante se verá que el presente análisis también se aparta del conjunto de fechas asociadas a Famabalasto Negro Grabado.

Con el fin de obtener nuevos elementos para aportar al análisis del sitio RCh 18 y sus fechados, se planificaron trabajos de excavación en el R2. Las tareas continuaron en la temporada 2008, completando la superficie intramuros de la estructura, que se excavó estratigráficamente y en área extendida hasta alcanzar los niveles estériles. Se lograron definir relictos de un piso de ocupación de sedimento compacto y el agujero de poste central. Se recuperaron escasos carbones dispersos pero lamentablemente ninguna estructura de combustión. Además de los hallazgos cerámicos se obtuvieron especímenes óseos de fauna, un bolo de pigmento rojo, unos pocos artefactos líticos sin formatizar, dos piedras planas con manchas de pigmento rojizo y un topu de hueso de unos $15 \mathrm{~cm}$ de largo, con cabecita circular deprimida en el centro.
La cerámica de la primera excavación se unió al nuevo conjunto logrando un total de 202 fragmentos, agrupados en 51 familias de fragmentos. Al observar el remontaje de tiestos procedentes de todos los niveles, se decidió cuantificar a la cerámica como un único conjunto. De acuerdo con el cómputo por familias la cerámica santamariana en conjunto es la mayoría, con casi un 59\%, incluyendo varios fragmentos de un puco Santa María indeterminado, concentrados hacia el centro de la estructura y también partes de cuello y borde de diferentes urnas Santa María Tricolor de la fase III. En conjunto, la cerámica Santa María Tricolor alcanza una proporción cercana al 22\%. Por su parte la Santa María Bicolor tiene una proporción inferior, del orden del $8 \%$. En otro trabajo, hemos propuesto que estos grandes fragmentos de cuellos de urna pueden haber tenido alguna funcionalidad como parte del conjunto de vasijas de servicio (Greco et al. 2011). El Famabalasto Negro Grabado representa una cantidad cercana al 12\% (Figura 4).

Si bien no se obtuvieron carbones apropiados para realizar un nuevo fechado del piso, la excavación en área fue provechosa, al permitir observar la asociación de familias de fragmentos con un alto nivel de agrupamiento en el piso de un recinto, de cerámica Santa María Bicolor, Tricolor fase III y Famabalasto Negro Grabado. ${ }^{14}$ Una vez definido el estrato esteril por debajo del piso y los cimientos del muro, se profundizó la excavación en toda el área para descartar la existencia de otra clase de estructuras. Esto permitió detectar una importante concentración muy posiblemente natural- de grandes trozos de carbón leñoso identificados como algarrobo (B. Marconetto, com. pers.) sin ceniza u otros materiales. Si bien la secuencia estratigráfica no daba lugar a duda acerca de la anterioridad de la depositación de estos carbones y la independencia de este evento respecto de la construcción

\footnotetext{
${ }^{14}$ De acuerdo con las propuestas de seriación de urnas Santa María, las fases IV y V -las más tardías en la serie-, habrían circulado en épocas de las expansiones incaica y española en el territorio (Perrotta y Podestá 1974; Weber 1978), observación respaldada por asociaciones contextuales con material incaico, hispanoindígena y europeo. Con respecto a las transformaciones en las proporciones, diseños y usos notados en el conjunto de urnas definido como fase III, Perrotta y Podestá (1974) plantearon que podrían haberse originado tempranamente a partir de la influencia incaica en la zona, hipótesis que aún no ha sido evaluada adecuadamente.
} 


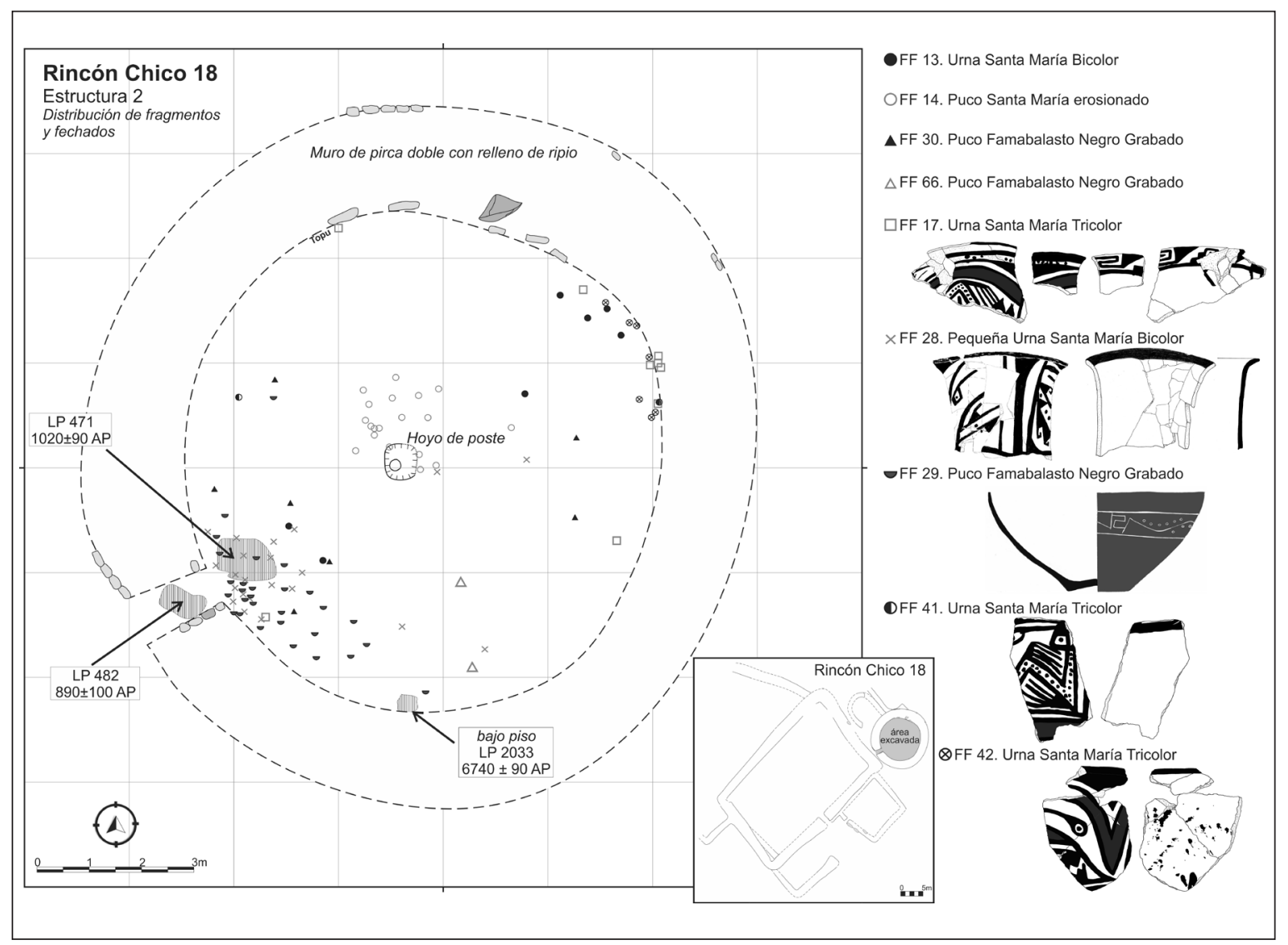

Figura 4. Planta del Recinto 2 de Rincón Chico 18 con la dispersión de los hallazgos cerámicos ilustrados.

del R2, decidimos realizar un fechado radiocarbónico sobre este material para contribuir a la evaluación de una antigüedad máxima de la construcción de R2. Sin embargo el valor resultó mucho más antiguo de lo esperado, $6740 \pm 90$ AP (LP 2033) y lamentablemente no fue útil para el propósito que lo requería. Su asociación a la cerámica del piso del recinto es claramente inexistente.

\section{* SínTESIS Y DisCUSIÓN}

A partir de las asociaciones discutidas para cada uno de los sitios con cerámica Famabalasto Negro Grabado, se puede tomar en cuenta la información disponible para interpretar la columna cronológica resultante. En la Figura 5 se han graficado las distribuciones probabilísticas de los fechados calibrados, representando en negro aquellos para los cuales se evaluó una aceptable asocia- ción con la cerámica FNG (grado II) y en gris aquellos en los que se planteó que la asociación es menor (grados III y IV). ${ }^{15}$ Se hace de esta forma más claramente visible el hecho de que la mayoría de las fechas con buen nivel de asociación a la cerámica FNG se concentran alrededor del 700-400 AP, mientras que las que se alejan del conjunto en ambos extremos tienen un grado menor de asociación. La excepción son los fechados de Rincón Chico 18 que, como se relató anteriormente, se apartan de lo esperado para esa localidad (Greco 2007). Asimis-

\footnotetext{
${ }^{15} \mathrm{Al}$ respecto, se hace notar la inexistencia de contextos con asociaciones de grado I, situación que se relaciona con las características de desempeño de la cerámica FNG, que por forma y tipo de pasta es inapropiada para su empleo sobre el fuego, razón por la cual difícilmente se la encuentre asociada funcionalmente a fogones. Tampoco se hallaron casos de fechados sobre adherencias orgánicas. Al mismo tiempo, ninguno de los entierros que contienen cerámica FNG han sido fechados.
} 


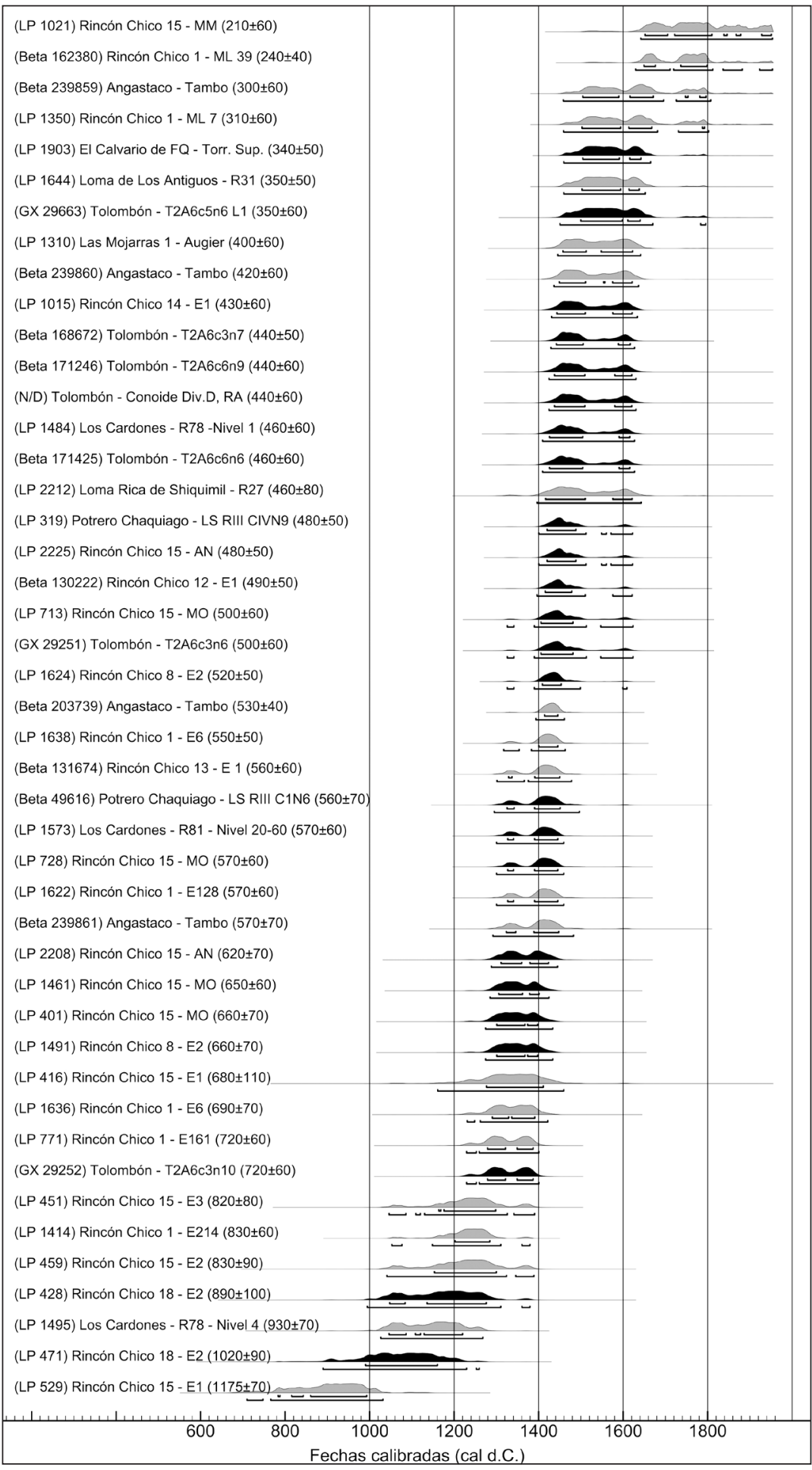

Figura 5. Fechados radiocarbónicos asociados a cerámica Famabalasto Negro Grabado. Las distribuciones de las calibraciones en negro corresponden a aquellos fechados que evaluamos con grado II de asociación con la cerámica; en gris aquellos con grado III o IV. Se excluyen los fechados informados como modernos. Curva de calibración SHCalo4 (McCormac et al. 2004); Software utilizado OxCal V4.1 (Bronk Ramsey 2009). 
mo, la diferencia entre las dataciones de Rincón Chico 18 y las otras con un grado probable (II) de asociación con cerámica es estadísticamente significativa (Palamarczuk 2011). ${ }^{16}$

La separación de los fechados del sitio RCh 18 con respecto a los restantes con buena asociación cerámica exige precaución en su empleo como dato para indicar la antigüedad del estilo FNG. Ese comportamiento anómalo motivó oportunamente la exclusión de los mismos en la elaboración de una secuencia cronológica para la cerámica del poblado de Rincón Chico (Greco 2007) y aquí se sigue también ese criterio. ${ }^{17}$ El caso del Recinto 2 de Rincón Chico 18 y sus fechas es sin duda especial. En principio es debido a las mismas que en otro momento hemos planteado que la cerámica FNG podría haberse elaborado desde los inicios del período Tardío (Palamarczuk y Manasiewicz 2009 [2001]). Conviene destacar aquí que, en los otros contextos con resultados relativamente "tempranos" (Rincón Chico 15 E1, E2 y E3; Rincón Chico 1 E6, E161 y E214; Los Cardones R78, Nivel 4), solo se recuperó un fragmento de cerámica FNG, por lo que la asociación con el estilo no puede asegurarse. No es extraño entonces que los fechados se aparten del conjunto. Sin embargo en Rincón Chico 18 se halló importante cantidad de esta cerámica y con alto nivel de remontaje, por lo tanto se plantea aquí que el problema radicaría en las dataciones en sí. Hay que tener presente que ninguna de las dos fechas provienen de un fogón o rasgo delimitado, con lo cual el grado de asociación muestra-evento es solo probable o poco probable. Por otro lado, es necesario comentar que estas fechas resultan también problemáticas si consideramos el conjunto cerámico del recinto en su totalidad, dado que son demasiado antiguas de acuerdo a la temporalidad teórica de las urnas Santa María Bicolor

16 Se siguió el procedimiento estadístico de Wilson y Ward (1981), basado en encontrar la razón de máxima probabilidad de agrupamiento entre series de fechados, realizando separaciones entre subgrupos cuando el valor del test sea inferior al nivel de 0,05 de significancia de $\chi^{2}$ (Chi cuadrado). De este modo, se encontraron cinco grupos, estando el más antiguo integrado solamente por las dos fechas de $\mathrm{RCH} 18$.

${ }^{17}$ En esa propuesta, la cerámica Famabalasto Negro Grabado está presente desde la fase 2 hasta el final de la secuencia. El inicio de la fase 2 es estimado entre el 1255 y el 1350 DC, con un $95,4 \%$ de probabilidad. y Santa María Tricolor fase III, de las cuales se hallaron fragmentos grandes sobre el piso.

Las descripciones expuestas marcan que en los diferentes ámbitos evaluados en poblados tardíos se reiteran las asociaciones de la cerámica Famabalasto Negro Grabado con estilos cerámicos del tardío local. En particular, destacamos las excavaciones en los sitios RCh 8, 18 y El Calvario de Fuerte Quemado, ya que mostraron asociaciones de cerámica FNG con estilos locales como la cerámica Ordinaria peinada y alisada, Santa María Bicolor y Santa María Tricolor fase III. ${ }^{18}$ La presencia de estilos incaicos en estos contextos es inexistente o bien escasa, ejemplos de esta última situación se dan en Tolombón, RCh 14, Los Cardones y Las Mojarras 1-Augier. Todos estos ámbitos incluyen tanto espacios domésticos, como productivos y ceremoniales, lo que evidencia la diversidad de situaciones y escenarios en los que esta cerámica -especialmente apropiada para el servicio de bebidas y alimentos - circulaba y se utilizaba. El sitio incaico Potrero Chaquiago en Andalgalá muestra una estructura del registro cerámico completamente diferente a la de los poblados tardíos. Allí los fragmentos FNG son muy escasos y se asocian con estilos fase inca como Famabalasto Negro sobre Rojo (muy abundante) o Yavi (escasa) y también con estilos incaicos en gran proporción.

El estudio crítico de la totalidad de los datos disponibles y su análisis estadístico, nos permite plantear que la vigencia del estilo como manifestación regional se ubicaría entre inicios del siglo XIV y mediados del siglo XVI (ver Figura 3). Este rango surge de un ejercicio cauteloso en el que, a través de distintas etapas, se van jerarquizando los datos más confiables, al considerar por un lado las dataciones con buenos niveles de asociación muestraevento y fechado-cerámica, así como las probabilidades estadísticas de asociación ente los propios fechados y la concordancia entre el resultado y el conocimiento acerca de la vigencia temporal de otros estilos cerámicos vinculados en cada caso. De todos modos reconocemos que

\footnotetext{
${ }^{18}$ Los pucos tricolores con dibujos en el interior se consideran hipotéticamente contemporáneos a la fase III, al apreciarse similares fenómenos de cambio estilístico con incorporación de elementos luego muy reiterados en el conjunto Santa María Bicolor, como las guardas interiores geométricas y los mencionados dibujos dentro de los pucos.
} 
dada la naturaleza probabilística de los métodos de datación, hablar de fechas concretas solo es posible como un recurso heurístico.

El Famabalasto Negro Grabado comenzaría a expandirse como un fenómeno de innovación estilística local en un momento intermedio-final del Tardío, con puntos de contacto con los cambios en el estilo Santa María que definen a la fase III. Otro fenómeno importante de esta época sería la declinación en la producción de las alfarerías San José y Shiquimil y probablemente también Loma Rica y otras de los comienzos del período Tardío, aunque este proceso pudo ser previo y requerirá de un tratamiento independiente. La producción del estilo parecería declinar en la época de contacto Hispano-Indígena.

Las observaciones sobre asociaciones de elementos ofrendados en 37 tumbas son coherentes con esta conclusión. En el análisis de contextos funerarios se estableció también una jerarquía de niveles de asociación, dada la tradición de entierros múltiples en cistas o cámaras sepulcrales que se utilizaban a través de un lapso variable que podía implicar muchas generaciones. ${ }^{19} \mathrm{Con}$ respecto a los estilos considerados tempranos dentro del período Tardío comentaremos que solamente se observaron tres casos de asociación con materiales Santa María Tricolor "clásicos" (una urna fase I-II y pucos). No se registraron asociaciones con San José, Shiquimil, Peñas Azules, Lorohuasi, etc. La excepción es la presencia de pucos FNG en dos cistas colectivas con pucos Loma Rica, lo que se puede vincular al uso a lo largo de un tiempo prolongado de dichos sepulcros. El conjunto más numeroso de asociaciones se dan con alfarería Santa María Bicolor y otros estilos que remiten a momentos tardíos dentro de la época tardía, destacando la inexistencia de vinculaciones con cerámica Inca decora-

\footnotetext{
${ }^{19}$ La escala tripartita incluye las siguientes categorías: I. Altamente probable: Cuando hay una relación directa entre la cerámica (en este caso FNG) y algún otro elemento. Por ejemplo urna y puco tapa, puco en el interior de un entierro en urna o integrando las ofrendas en un enterratorio de un solo individuo. II. Probable: Cuando hay una relación espacial entre objetos que pertenecen a una ofrenda individual pero que se encuentra en una tumba múltiple. III. Dudoso o problemático: Cuando hay una relación espacial entre objetos que se encuentran dentro de un sepulcro, pero no se puede establecer con precisión cuáles pertenecen a una misma ofrenda (Palamarczuk 2011).
}

da. Finalmente registramos un solo caso de asociación con materiales de época Hispano-Indígena (puntas de hueso) (Palamarczuk 2011).

En gran medida, el panorama obtenido en el análisis actual se basa en los contextos del poblado de Rincón Chico y refleja la historia del estilo en ese núcleo en particular, ya que de los 47 fechados considerados, 26 corresponden al mismo. Es probable que las trayectorias del estilo sean diferentes en cada poblado, aunque esto no se pueda evaluar con los datos disponibles. De hecho, la producción del FNG debió comenzar en algún punto particular, para luego expandirse según distintos ritmos a través de los asentamientos de la región. De todos modos, los fechados asociados a FNG de otros sitios en la región se ajustan a lo observado en Rincón Chico, por lo que estos resultados son útiles para valorar su temporalidad a una escala regional, particularmente en lo que respecta al valle de Yocavil. Para el área de Hualfín, solo se consideraron datos del poblado de Loma de los Antiguos y será muy importante incorporar información de otros asentamientos.

Reflexionando acerca del proceso de innovación relacionado con el estilo de nuestro estudio y la época que representa, y considerando además que las trayectorias de su desarrollo pudieron ser diferentes en cada área y localidad, hay que pensar en múltiples posibilidades. Si bien a partir de los datos analizados adherimos a una cronología dentro de la época tardía para el FNG, nos preguntamos si el Famabalasto Negro Grabado es una perduración de estilos negro pulido que caracterizaron al Formativo regional, tal como lo sugiriera Serrano (1967).

La observación de continuidades en ciertas temáticas y modos de representación, por ejemplo los modos de representación de la humanidad entre las vasijas tardías y las pretardías de Yocavil (Bugliani 2004), invita a considerar la posibilidad de perduraciones -a través de un tiempo largo- de contenidos significativos presentes en lo profundo de diversas manifestaciones estéticas con peculiaridades materiales que las distinguen, pero con elementos de significación que las integran. Pero en el caso de los paralelismos entre las alfarerías negras y grises tempranas y el Famabalasto Negro Grabado, ipodemos hablar de continuidades sin interrupción o estamos ante el resurgir de pautas estilísticas 
"antiguas" luego de un tiempo de abandono? De algún modo los resultados del presente análisis apuntan a esta última posibilidad.

Podríamos pensar en una revivificación de ciertos modelos, luego de un período de desuso, a partir de la memoria histórica de la sociedad acerca de antiguas consignas estéticas y valores sociales que se pretendieron destacar en ese presente a través de la reedición de una estética reelaborada en un nuevo estilo. No obstante, viejas pautas estilísticas pudieron desaparecer del escenario regional y conservarse solo en algún punto en el cual continuaron reproduciéndose y transformándose, para luego, en cierto momento, cobrar nuevo impulso $\mathrm{y}$ alcance regional. Es una idea interesante, que queda pendiente como posibilidad y que incluye en sí también una relación con los complejos procesos de activación de la memoria colectiva. De cualquier manera, en tanto fenómeno de magnitud regional, el estilo parece manifestarse hacia mediados-finales del período Tardío. Los paralelos con alfarería previa, no solo de la región sino también de otros puntos del área surandina, son innegables. Son algunos ejemplos los pucos Candelaria con decoración incisa formando guardas en sus bordes, las cerámicas San Pedro Negro Grabado de San Pedro de Atacama que poseían diseños geométricos y aplicaciones de sustancias blancas rellenando las decoraciones grabadas (Tarragó 1976: 55), las cerámicas grises y negras pulidas del formativo de Yocavil con decoración incisa, también en forma de bandas ubicadas en los bordes ( $\mathrm{Ta}$ rragó 1976: 73, fig. 20). ${ }^{20}$

Sin embargo, a la vez que evoca estilos previos, el Famabalasto Negro Grabado es una manifestación expresiva con carácter propio y, en su originalidad, también resulta novedosa y muy contrastante con otros estilos contemporáneos (de cocción oxidante en su mayoría). Su estética toma algunos elementos de viejos modelos, sin constituir copias de ellos. Posee afinidades que lo vinculan con tradiciones presantamarianas, sumándose a la tendencia de una época de cambios estilísticos en la que se reactivan antiguos elementos simbólicos, una ten-

\footnotetext{
${ }^{20}$ De alguna manera los problemas de catalogación de la cerámica Famabalasto Negro Grabado observados en diferentes depósitos de museos y catálogos, donde muchas veces se lo identifica como un estilo formativo, evidencian esos paralelos estéticos.
}

dencia quizás vinculada con procesos locales o regionales de cambio político. De algún modo, el impulso del estilo puede estar prefigurando posteriores y sucesivas $-y$ en algún tramo de la historia también contemporáneasrenovaciones de viejos temas del ámbito local y andino como los relacionados a las figuras del felino (Reynoso y Pratolongo 2008), del guerrero-sacrificador, las cabezas cercenadas y las aves voladoras, que vuelven a cobrar un notorio protagonismo, luego de un lapso de desuso, a través de su representación en diferentes soportes materiales hacia finales del período Tardío y en la época de expansión incaica (Palamarczuk 2011).

La elaboración y circulación del estilo FNG se encuentra muy acotada espacialmente en el área valliserrana del NOA, con especial énfasis en el valle de Yocavil y alrededores, y, si bien es posible que existan ejemplares subidentificados en colecciones de otras áreas, su distribución fuera de esta zona debió ser muy limitada. Es interesante destacar entonces que esta expresión local parece estar acompañando un fenómeno que lo incluye pero también lo excede y que alcanzó una magnitud regional andina, este es, la producción de alfarerías finas negras y pulidas, en algunos casos también incisas y con rellenos blancos y otras aplicaciones de resinas o pinturas, que, con características peculiares en los diferentes contextos culturales de producción, definieron un singular gusto o tendencia estética coincidente en diferentes puntos del área hacia finales del período Tardío o Intermedio Tardío y especialmente en momentos de expansión incaica.

Retomando aspectos metodológicos de esta propuesta, consideramos que es fundamental el establecimiento de buenos niveles de asociación para extraer conclusiones mínimamente fundamentadas a partir de los fechados - un elemento que buscamos poner en relieve a través de las descripciones de casos y en la jerarquización de los datos propuesta. El manejo de una muestra importante de dataciones, reunida a lo largo de décadas de investigación, y el análisis estadístico de la misma, permitió detectar aquellas que se apartan de las tendencias generales y diseñar nuevos trabajos de campo tendientes a evaluar su calidad. Sería muy importante avanzar en el futuro sobre diseños de muestreo que incluyan contextos con buenas asociaciones con cerámica, como por ejemplo enterratorios simples u ofrendas vinculables a 
individuos. Asimismo convendría sumar fechados que se vayan generando en zonas aledañas a Yocavil, como los valles del Cajón, Calchaquí, Tafí y el piedemonte oriental. El análisis de los contextos con fechados radiocarbónicos sirvió para lograr un panorama, que si bien nunca será completo y será susceptible de modificaciones conforme se produzca nueva evidencia, se funda en la integración de un importante conjunto de información disponible en la actualidad.
Agradecimientos Queremos expresar nuestro agradecimiento a los participantes en las excavaciones del sitio Rincón Chico 18: Marina Marchegiani, Alina Álvarez Larraín, Juan Pablo Carbonelli, Sol Grimoldi, Fernando Cabrera, Miguel Mena y Juan Mena. Asimismo a Myriam Tarragó por sus observaciones a una versión previa del trabajo y a Alina Palamarczuk por la traducción del resumen. Dedicamos este trabajo a la memoria de María Delia Arena.

\section{* Referencias citadas}

ALCINA FRANCH, J., 1982. Arte y Antropología. Alianza Editorial, Madrid.

APPAdURAI, A., 1991 [1986]. La vida social de las cosas. Perspectiva cultural de las mercancías. Grijalbo, Méjico.

BAIGORRIA, J., F. CABRERA, C. GRECO, P. OCHOA y V. PALAMARCZUK, 2005. Análisis cerámico y arquitectónico de Rincón Chico 8, Valle de Santa María, Catamarca. Actas del IX Congreso Nacional - II Latinoamericano de Estudiantes de Arqueología (formato CD), Córdoba.

BARKER, P., 1977. Techniques of Archaelogical Excavation. Batsford, Londres.

BAUER, B. S., 2002. Las antiguas tradiciones alfareras de la región del Cuzco. Editorial Centro Bartolomé de Las Casas, Cuzco.

BUGLIANI, M. F., 2004. Formas y recursos estilísticos para la representación humana durante el formativo en el valle de Santa María.Acta Americana 12 (1): 79-88.

BRONK RAMSEY, C., 2009. Bayesian analysis of radiocarbon dates. Radiocarbon 51 (1): 337-360.

CALDERARI, M., y V. WILLIAMS, 1991. Re-evaluación de los estilos cerámicos incaicos en el Noroeste Argentino. El imperio inka. Actualización y perspectivas por registros arqueológicos y etnohistóricos, vol II: 74-95.

CARBONARI, J., 1994. Asociación muestra-evento en C14. En Jornadas de Arqueología e Interdisciplinas, pp. 81-85. PREP/CONICET, Buenos Aires.

CIGLIANO, E. M., 1956-57. Investigaciones arqueológicas en la zona de Famabalasto (Provincia de Catamarca). Runa VIII, Parte Segunda: 241-269.
1958. Arqueología de la zona de Famabalasto. Departamento de Santa María. (Provincia de Catamarca). Revista del Museo de La Plata (Nueva Serie) 24: 29-122.

CREMONTE, B., y V. WILLIAMS, 2007. La construcción social del paisaje durante la dominación inka en el Noroeste Argentino. En Procesos sociales prehispánicos en el sur andino. La vivienda, la comunidad y el territorio, A. E. Nielsen, M. C. Rivolta, V. Seldes, M. M. Vázquez y P. H. Mercoli (Comps.), pp. 207-236. Editorial Brujas, Córdoba.

CREMONTE, B., V. WILLIAMS y A. DÍAZ, 2010. Cuencas de Angastaco-Molinos. Una aproximación al control inca a partir de la producción cerámica. En Arqueología Argentina en el Bicentenario de la Revolución de Mayo. XVII Congreso Nacional de Arqueología Argentina, J. R. Bárcena y H. Chiavazza (Eds.), pp. 1285-1290. Facultad de Filosofía y Letras-UNCuyo y INCIHUSA-CONICET, Mendoza.

CORNELL, P., y N. JOHANSSON, 1993. Desarrollo del asentamiento del Sitio STucTav 5 (El Pichao). Provincia de Tucumán, comentarios sobre dataciones de $14 \mathrm{C}$ y luminiscencia. Publicaciones 2, Investigaciones 1: 31-43.

DE LA FUENTE, G. A., K. L. RASMUSSEN, J. R. FERGUSON y M. D. GLASCOCK, 2010. Cronología por termoluminiscencia (TL) de cerámicas pertenecientes al Horizonte Inka (ca. AD 1480 - AD 1532) y el Período Tardío (ca. AD 900 - AD 1450) en el sur del valle de Abaucán: Análisis comparativos y resultados preliminares (Dpto. de Tinogasta, Catamarca, Argentina). En Arqueología Argentina en el Bicentenario de la Revolución de Mayo. XVII Congreso Nacional de Arqueología Argentina, J. R. Bárcena y H. Chiavazza (Eds.), pp. 1339-1344. Facultad de Filosofía y LetrasUNCuyo y INCIHUSA-CONICET, Mendoza.

FIGINI, A. J., 2004. Métodos y técnicas de la datación radiocarbónica para arqueólogos y geocientíficos. LATYR, UNLP, La Plata. 
GONZÁLEZ, A. R., 1950-55. Contextos culturales y cronología relativa en el área Central del N.O. Argentino (Nota Preliminar). Anales de Arqueología y Etnología XI: 7-32 y láminas.

1977. Arte precolombino de la Argentina. Introducción a su historia cultural. Ediciones Valero, Buenos Aires.

1992. Las placas metálicas de los Andes del Sur. Contribución al estudio de las religiones precolombinas. Verlag Philipp von Zabern, Mainz am Rhein.

GONZÁLEZ, L. R., R. DORO, P. CORVALÁN, N. GROSMAN, M. TANCREDI y A. VARGAS, 2002. Investigaciones en el sitio 12 de Rincón Chico, Valle de Yocavil (Catamarca). Actas del XIII Congreso Nacional de Arqueología Argentina, tomo II: 375-383.

GONZÁLEZ, L. R., y R. DORO, 2004. Jardines de piedras. Estructuras ceremoniales en Rincón Chico (Provincia de Catamarca). Etnía 46-47: 147-168.

GONZÁLEZ, L. R., y M. TARRAGÓ, 2005. Vientos del sur. El valle de Yocavil (Noroeste Argentino) bajo la dominación incaica. Estudios Atacameños 29: 67-95.

GRECO, C., 2007. Secuencias radiocarbónicas y estilos cerámicos en Rincón Chico, valle de Yocavil, Catamarca. Tesis de licenciatura, Facultad de Filosofía y Letras, Universidad de Buenos Aires, Buenos Aires.

2012. Integración de datos arqueológicos y geofísicos para la construcción de una cronología absoluta de Yocavil y alrededores. Tesis de doctorado, Facultad de Filosofía y Letras, Universidad de Buenos Aires, Buenos Aires.

GRECO, C., M. MARCHEGIANI y V. PALAMARCZUK, 2011. Tipologías estilísticas e inferencias funcionales de objetos cerámicos en momentos tardíos del Noroeste Argentino. En Las manos en la masa. Arqueologías y antropologías de la alimentación en Suramérica, P. Babot, F. Pazzarelli y M. Marschoff (Eds.). En prensa.

GRIMOLDI, S., M. MARCHEGIANI, V. PALAMARCZUK, G. PRATOLONGO y A. REYNOSO, 2008 Ms. El Calvario de Fuerte Quemado. Famabalasto. Prospección, relevamiento arquitectónico y excavación. Informe de campaña (11 al 30 de marzo de 2007) y análisis preliminares. Manuscrito en poder de los autores.

IBARRA GRASSO, D. E., 1967. Argentina Indígena \& Prehistoria Americana. TEA, Buenos Aires.

KLIGMANN, D. y A. M. ALBINO, 2007. Análisis de los restos óseos de reptiles hallados en una vasija cerámica, Tolombón,
Salta. XVI Congreso Nacional de Arqueología Argentina, tomo I: 479-481.

LÓPEZ, S., y R. SPANO, 2006. Nuevos datos sobre la ocupación tardía del Valle de Yocavil. Excavaciones en el sitio Rincón Chico 1 (Pcia. de Catamarca). Entre pasados y presentes. Trabajos de las VI Jornadas de Jóvenes Investigadores en Ciencias Antropológicas (Formato CD). Instituto Nacional de Antropología y Pensamiento Latinoamericano, Buenos Aires.

MARCHEGIANI, M., 2011. Las formaciones sociales de Yocavil durante la dominación inca y la conquista española. Contacto, conflicto, persistencia y transformaciones (siglos XV-XVII DC). Tesis de doctorado, Facultad de Filosofía y Letras, Universidad de Buenos Aires, Buenos Aires.

MARCONETTO, M. B., 2007. Aportes de la antracología a la cronología del valle de Ambato. En Paleoetnobotánica del Cono Sur: Estudios de casos y propuestas metodológicas, B. Marconetto, P. Babot y N. Oliszewski (Comps.). Museo de Antropología, Facultad de Filosofía y Humanidades, Universidad Nacional de Córdoba, Córdoba.

MCCORMAC, F. G., A. G HOGG, P. G. BLACKWELL, C. E. BUCK, T. F. G. HIGHAM y P. J. REIMER, 2004. ShCalo4 Southern Hemisphere Calibration, o-11.o Cal Kyr BP. Radiocarbon 46 (3): 1087-1092.

NIELSEN, A. E., 1997. Tiempo y Cultura Material en la Quebrada de Humahuaca. 700-1650 DC. Instituto Interdisciplinario Tilcara, Facultad de Filosofía y Letras, Universidad de Buenos Aires, Tilcara.

NOLAN, K., 2011. Temporal Hygiene: Problems in Fort Ancient Cultural Chronology. Current Research in Ohio Archaeology www. ohioarchaeology.org

ORTON, C., P. TYERS y A. VINCE, 1997. La cerámica en Arqueología. Ed. Crítica, Barcelona.

PALAMARCZUK, V., 2008. Un análisis de la cerámica arqueológica de cuatro sitios en el bajo de Rincón Chico. En Estudios arqueológicos en Yocavil, M. Tarragó y L. R. González (Eds.) pp. 19-80. Asociación de Amigos del Museo Etnográfico, Buenos Aires.

2011. Un estilo y su época. El caso de la cerámica Famabalasto Negro Grabado del Noroeste Argentino. BAR, International Series 2243. Archaeopress, Oxford.

PALAMARCZUK, V., y M. MANASIEWICZ, 2009 [2001]. Tiempos antiguos. Hacia una comprensión del proceso productivo de la cerámica Famabalasto Negro Grabado. Ponencia al XIV Congreso Nacional de Arqueología Argentina (2001). 
En Arqueología Argentina en los inicios de un nuevo siglo, tomo II, F. Oliva, N. de Grandis y J. Rodríguez (Comps.), pp. 405-417. Laborde Editor, Rosario.

PERROTTA, E. B., y C. PODESTÁ, 1974 Ms. Seriación con valor cronológico de una colección de urnas y pucos santamarianos del valle de Yocavil. Ponencia al III Congreso Nacional de ArqueologíaArgentina, Salta. Manuscrito en poder de los autores.

1975. Arqueología de la quebrada de Shiquimil. Actas y Trabajos I Congreso Nacional de Arqueología Argentina: 405-422. Buenos Aires.

PETTITT, P. B., W. DAVIES, C. S. GAMBLE y M. B. RICHARDS, 2003. Palaeolithic radiocarbon chronology: quantifying our confidence beyond two half-lives. Journal of Archaeological Science 30(12): 1685-1693.

PRATOLONGO, G. J., 2008. Estudio de los restos faunísticos de dos sitios tardíos en el valle de Yocavil, provincia de Catamarca: Rincón Chico 15 y Las Mojarras 1. En Estudios arqueológicos en Yocavil, M. Tarragó y L. R. González (Eds.), pp. 81 - 126. Asociación de Amigos del Museo Etnográfico, Buenos Aires.

QUIROGA, A., 1901. Ruinas calchaquíes, Fuerte Quemado. Anales de la Sociedad Cientifica Argentina 52: 235-243.

RAFFINO, R., 1991 [1988]. Poblaciones Indígenas en la Argentina. TEA, Buenos Aires.

REYNOSO, A., 2009. El color y el fuego: excavaciones en la plaza de la cumbre de Rincón Chico (Provincia de Catamarca). Comechingonia 12: 75-90.

REYNOSO, A., y G. PRATOLONGO, 2008. Jaguares de nuevo. Consideraciones sobre la temática filípica en la iconografía cerámica del período Tardío en Yocavil (Noroeste argentino). Estudios Atacameños 35: 76-96.

RIVOLTA, G., y J. SALAZAR, 2006. La cerámica como indicador de la utilización del espacio. Un estudio en el sitio "Los Cardones" (Pcia. de Tucumán). Comechingonia 9: 91-102.

SCHIAPPACASSE, V., A. ROMÁN, I. MUÑOZ, A. DEZAy G. FOCACCI, 1991. Cronología por termoluminiscencia de la cerámica del extremo norte de Chile: Primera parte. Actas del XI Congreso Nacional de Arqueología Chilena, tomo I: 43-59.

SERRANO, A., 1967. Historia cultural del Tucumán Prehispánico (una introducción a la Arqueología del Noroeste Argentino). Ampurias XXIX: 1-66.
STENBORG, P., 2001. Holding Back History. Issues of Resistance and Transformation in a Post-Contact Setting, Tucumán, Argentina c. A.D. 1536-1660. GOTARC Series B. Gothenburg Archaeological Theses, Göteborgs Universitet, Göteborgs.

TARRAGÓ, M. N., 1976. Alfarería típica de San Pedro de Atacama. Estudios Atacameños 4: 37-64.

1995. Desarrollo Regional en Yocavil: una estrategia de investigación. Hombre y Desierto 9 (1): 225-235.

1998. El patrimonio del valle de Santa María en peligro. En 50 años de aportes al desarrollo y consolidación de la antropología argentina. Homenaje a Alberto Rex González, pp. 205-253. Facultad de Filosofía y Letras-Fundación Argentina de Antropología, Buenos Aires. 2007. Ámbitos domésticos y de producción artesanal en el Noroeste Argentino. Intersecciones en Antropología 8: 87-100.

TARRAGÓ, M., S. F. RENARD y L. R. GONZÁLEZ, 1992. Proyecto arqueológico valle de Yocavil. Informe campaña 1992. Palimpsesto Revista de Arqueología 2: 133-138.

TARRAGÓ, M. N., L. R. GONZÁLEZ, P. CORVALÁN, R. A. DORO, M. MANASIEWICZ y M. J. PEÑA, 1998-99. La producción especializada de alimentos en el asentamiento Prehispánico Tardío de Rincón Chico, Provincia de Catamarca. Cuadernos del INAPL 18: 409-427.

URIBE, M., 2002. Sobre alfarería, cementerios, fases y procesos durante la prehistoria tardía del desierto de Atacama (800-1600 DC). Estudios Atacameños 22: 7-31.

WATERBOLK, H. T., 1983. Ten guidelines for the archaeological interpretation of radiocarbon dates. En Proceedings of the First International Symposium 14 C and Archaeology, W. G. Mook y H. T. Waterbolk (Eds.), pp: 57-70, Strasbourg.

WEBER, R., 1978. A seriation of the Late prehistoric Santa María cultura in Northwestern Argentina. Fieldiana Anthropology 68 (2): 49-98.

WILLIAMS, V. I., 1995. Arqueología incaica en la región centro-oeste de Catamarca (República Argentina). Tesis de doctorado, Facultad de Ciencias Naturales, Universidad Nacional de La Plata, La Plata

2003. Nuevos datos sobre la prehistoria local en la quebrada de Tolombón. Pcia. de Salta. Argentina. En Local, Regional, Global: prehistoria, protohistoria e historia en los Valles Calchaquies, P. Cornell y P. Stenborg (Eds.), Anales Nueva época 6: 163-219. Instituto Iberoamericano Universidad de Göteborg, Gotemburgo. 
2010. El uso del espacio a nivel estatal en el sur del Tawantinsuyu. En El hábitat prehispánico. Arqueología de la arquitectura y de la construcción del espacio organizado, M. E. Albeck, M. C. Scattolin y M. A. Korstanje (Eds.), pp. 77-114. FHyCS, UNJu, San Salvador de Jujuy.

WILSON, S. R., y G. K. WARD, 1981. Evaluation and clustering of radiocarbon age determinations: Procedures and paradigms. Archaeometry 23 (1): 19-39.
WYNVELDT, F., 2009. La Loma de los Antiguos de Azampay. Un sitio defensivo del Valle de Hualfin (Catamarca, Argentina). Sociedad Argentina de Antropología, Buenos Aires.

ZEIDLER, J. A., 2003. Formative Period Chronology for the Coast and Western Lowlands of Ecuador. En Archaeology of Formative Ecuador, J. S. Raymond y R. L. Burger (Eds.), pp. 487-527. Dumbarton Oaks Research Library and Collection, Washington, DC 